\title{
IMPACTS OF TIMING OF CROSSLINKER ADDITION ON WATER SHUT OFF POLYMER GEL PROPERTIES
}

\author{
A Thesis \\ by \\ PRASHANT SHRIWAL \\ Submitted to the Office of Graduate Studies of \\ Texas A\&M University \\ in partial fulfillment of the requirements for the degree of \\ MASTER OF SCIENCE
}

May 2012

Major Subject: Petroleum Engineering 
Impacts of Timing of Crosslinker Addition on Water Shut Off Polymer Gel Properties Copyright 2012 Prashant Shriwal 


\title{
IMPACTS OF TIMING OF CROSSLINKER ADDITION ON WATER SHUT OFF POLYMER GEL PROPERTIES
}

\author{
A Thesis \\ by \\ PRASHANT SHRIWAL
}

\author{
Submitted to the Office of Graduate Studies of \\ Texas A\&M University \\ in partial fulfillment of the requirements for the degree of \\ MASTER OF SCIENCE
}

Approved by:

Chair of Committee, Robert H. Lane

Committee Members, Jerome J. Schubert

Yuefeng Sun

Head of Department, Stephen A. Holditch

May 2012

Major Subject: Petroleum Engineering 


\begin{abstract}
Impacts of Timing of Crosslinker Addition on Water Shut Off Polymer Gel Properties.

(May 2012)

Prashant Shriwal, B.Tech., Kurukshetra University

Chair of Advisory Committee: Dr. Robert Lane
\end{abstract}

In preparation of gelant solution for making crosslinked polymer gels for water shutoff applications unpublished experiments plus chemical intuition suggest that, unless hydrolyzed polyacrylamide (HPAM) polymer is fully hydrated before addition of crosslinker, the final gel will have lower than optimum mechanical strength. It is suggested so because polymer chains need to be unfolded before proper crosslinking can occur. We have evaluated gel strengths of "flowing" gels for water shut off in natural fractures and other non-matrix features as a function of time of addition of crosslinker relative to time of hydration of polymer. Gels were prepared from moderately high molecular weight HPAM crosslinked with chromium(III) acetate (CrAc) or polyethyleneimine (PEI). Crosslinker was added after either (1) initial wetting of solid polymer particles or (2) complete hydration of polymer.

Dry solid HPAM is often preferred because of lower overall cost of active material and smaller storage footprint than slurry or liquid concentrates. The down side 
of using the solid product is that it generally requires two or more large blending tanks in order to fully hydrate polymer for large volume gel treatments.

Gel strengths were determined using a common qualitative coding system for gels prepared in identical manner except for timing of crosslinker addition. Samples were prepared in fresh water or $4 \% \mathrm{NaCl}$ brine and at ambient temperature or $122^{\circ} \mathrm{F}$.

For almost all samples of polymer gels prepared with identical concentrations of HPAM and CrAc, there was no observable difference in gel strength regardless of time of addition of crosslinker. HPAM/CrAc polymer gels with $4 \mathrm{wt} \% \mathrm{NaCl}$ make up water were lower in strength by one code level with respect to those prepared with fresh water. For polymer gels hydrated at $122{ }^{\circ} \mathrm{F}$ with $4 \mathrm{wt} \% \mathrm{NaCl}$ there was no gel strength code level difference with respect to those prepared at ambient temperature with $4 \mathrm{wt} \% \mathrm{NaCl}$.

For HPAM/PEI polymer gels the majority of the samples showed similar gel strengths regardless of the timing of crosslinker addition. A few polymer gels showed weaker gel strengths when prepared from partially hydrated polymer solution before crosslinker addition. Presence of $4 \mathrm{wt} \% \mathrm{NaCl}$ in the makeup water gave weaker gel strengths than those prepared with fresh water with an average difference of four code levels.

Results of this work demonstrate that for most field applications optimum quality gel can be obtained using dry polymer and a small continuous mixing system for initial wetting of the polymer after which the crosslinker can be added to the polymer solution on the fly. This practice can decrease the footprint and cost of large volume flowing gel treatments. 


\section{DEDICATION}

This thesis is dedicated to my parents, Pratap and Sunehari Shriwal, for their unwavering and selfless love, support and direction throughout my life. 


\section{ACKNOWLEDGEMENTS}

I would like to begin by thanking my committee chair, Dr. Robert Lane for his support during the entire duration of this project. I have cherished each and every conversation I have had with him regarding this project. He has been a treasure trove of knowledge and his encouragement during the critical stages of experimentations gave me tons of confidence. I am thankful to him for providing me graduate fellowship and student worker during the course of this project.

I would also like to thank my committee members Dr. Jerome Schubert and Dr. Yuefeng Sun. I would like to thank our department's facility coordinator, John Maldonado. I would also like to thank Kemira Industries for providing us with the commercial grade Polyethyleneimine(PEI). I want to extend my gratitude to my teammates for providing their valuable insights during the course of this project.

Lastly, I would like to thank all my friends for their support and motivation. 


\section{TABLE OF CONTENTS}

Page

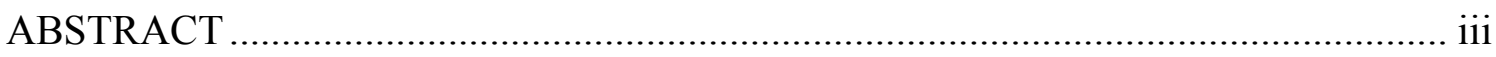

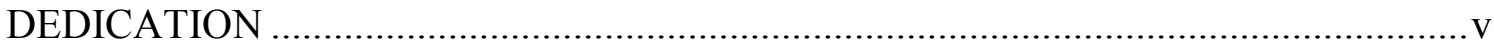

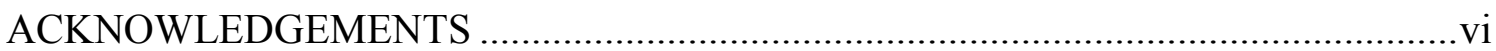

TABLE OF CONTENTS ............................................................................... vii

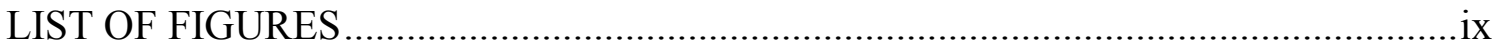

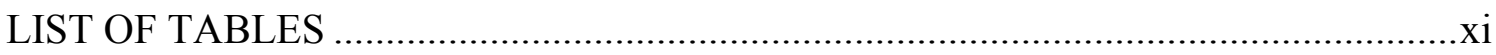

1. INTRODUCTION AND LITERATURE REVIEW .............................................. 1

1.1 Excessive water production in petroleum reservoirs .......................................... 1

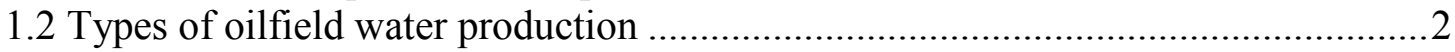

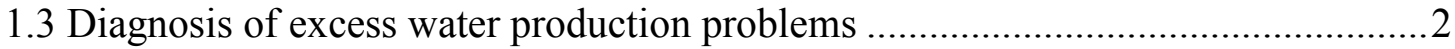

1.3.1 Excessive water production due to influx through fractures connected to

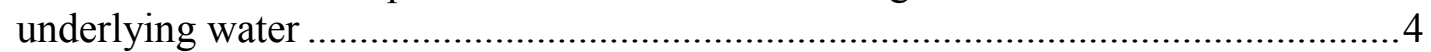

1.3.2 Excessive water production due to fracture channeling.................................. 4

1.4 Techniques to decrease excess water production .................................................5

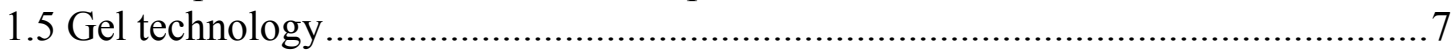

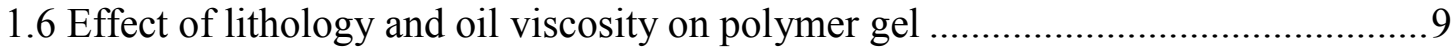

1.7 Polymer (HPAM) handling during field operations ......................................... 10

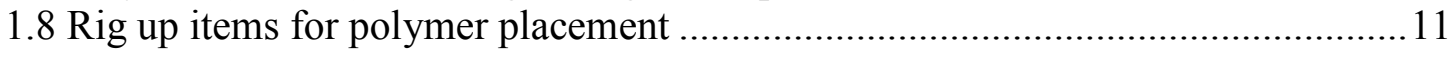

2. STATEMENT OF PROBLEM AND BACKGROUND THEORY ...........................13

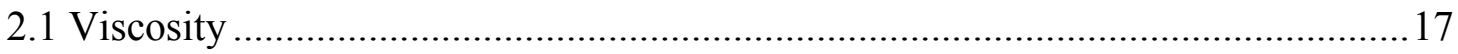

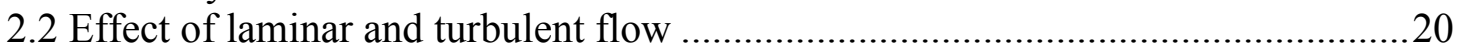

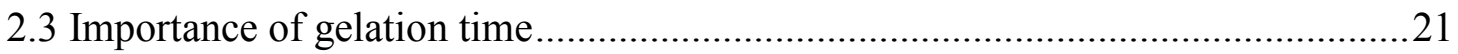

2.4 Behavior of organically crosslinked polymer gels ..........................................21

2.4.1 Effect of temperature on HPAM/PEI polymer gels ...................................21

2.4.2 Effect of salinity on HPAM/PEI polymer gels ............................................22

2.4.3 Effect of polymer concentration on HPAM/PEI polymer gels .......................22

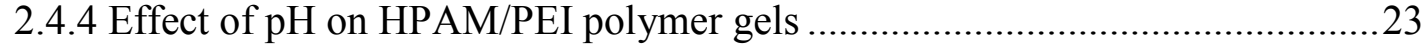

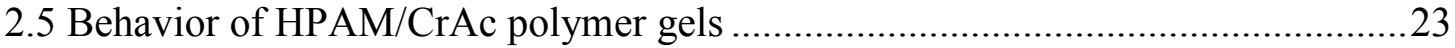

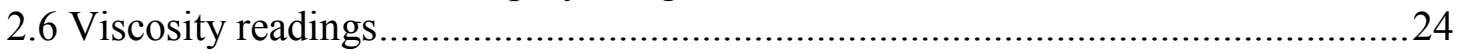

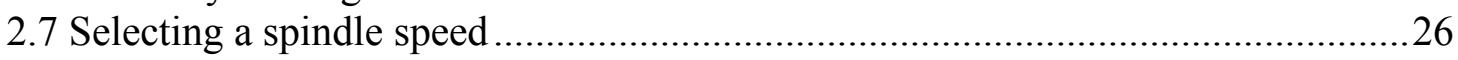

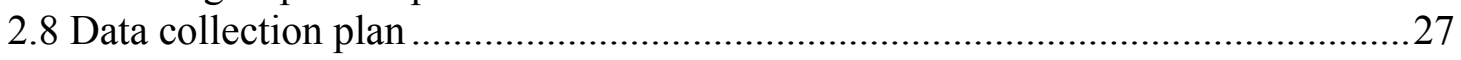


3. EXPERIMENTAL PROCEDURE AND EQUIPMENT ………………......................29

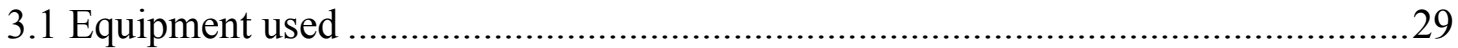

3.2 Material used for conducting experiments ……………......................................32

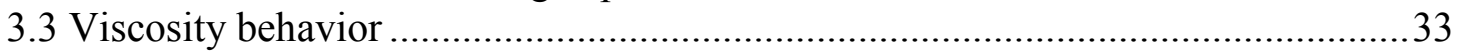

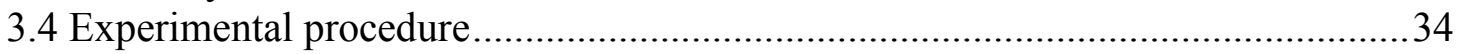

3.4.1 Polymer/Crosslinker solution preparation ......................................................34

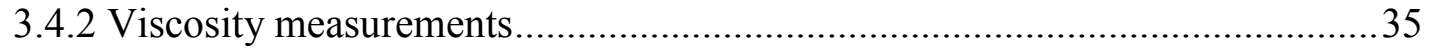

3.4.3 Determining gel strength code ........................................................................

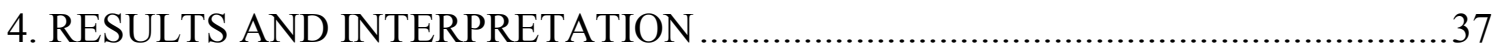

4.1 Organically crosslinked gels - Hydrated at ambient temperature .............................37

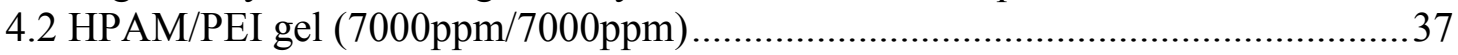

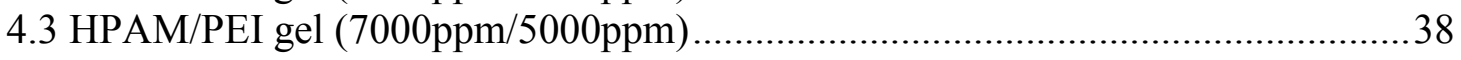

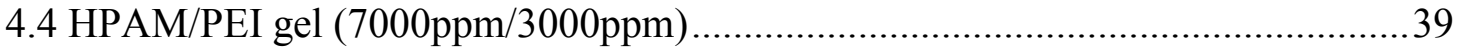

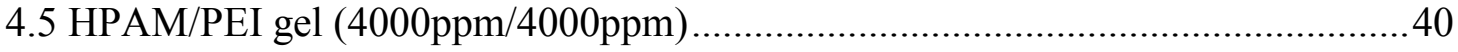

4.6 HPAM/PEI gel (9000ppm/6000ppm) ............................................................

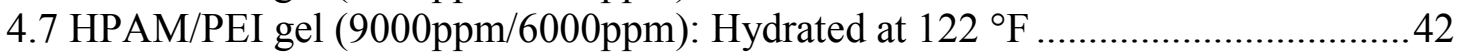

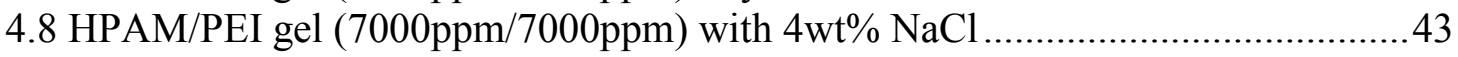

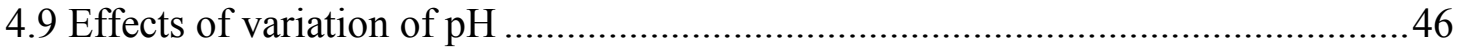

4.10 Effect of hydration temperature ........................................................................4

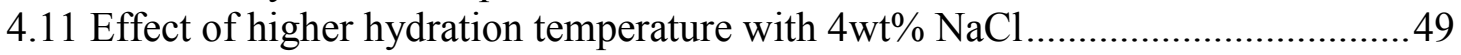

4.12 Origanically crosslinked polymer gels prepared with research grade PEI ............52

4.13 Viscosity of pre-gel polymer solution ……………........................................52

4.14 Inorganically crosslinked polymer gels ...........................................................57

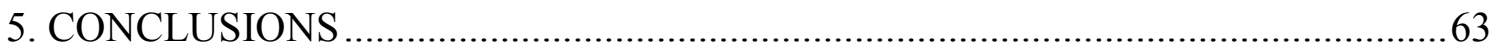

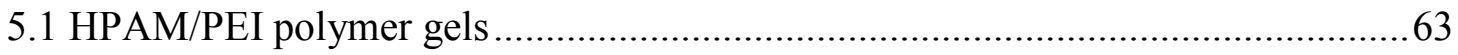



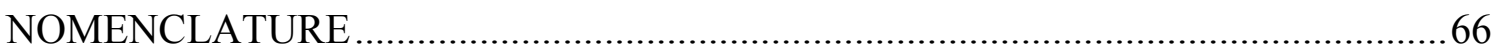

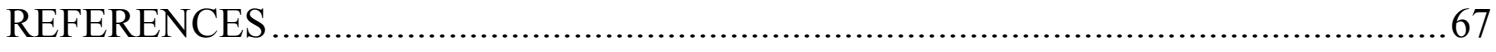

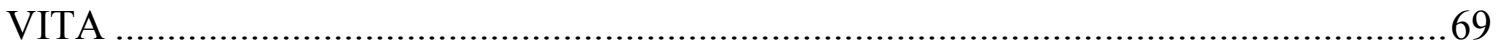




\section{LIST OF FIGURES}

Page

Fig. 1-Fracture network coning ......................................................................... 4

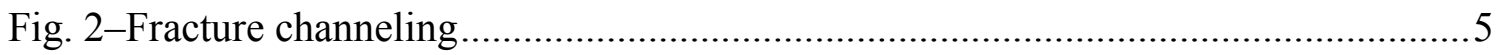

Fig. 3-Complexation of carboxylate group on polymer chains by chromium species

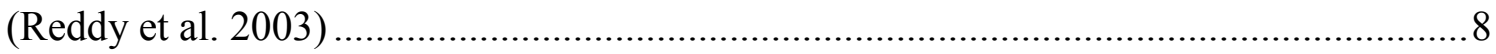

Fig. 4-Gelation mechanism between PAM and PEI (Reddy et al. 2003) ...................... 9

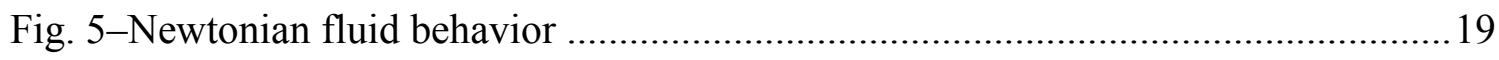

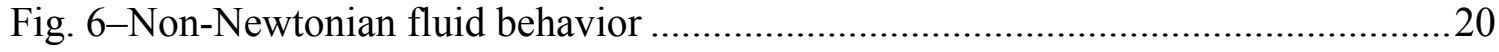

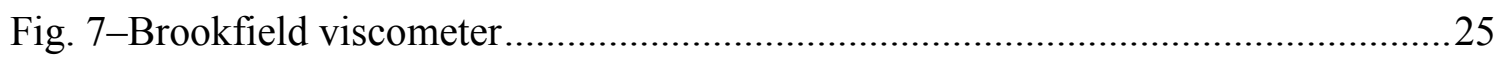

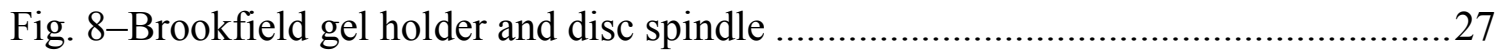

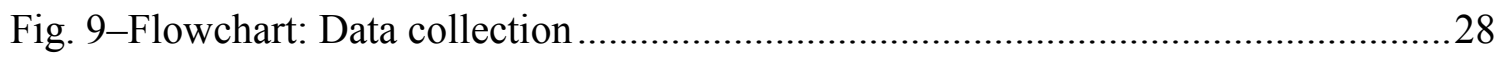

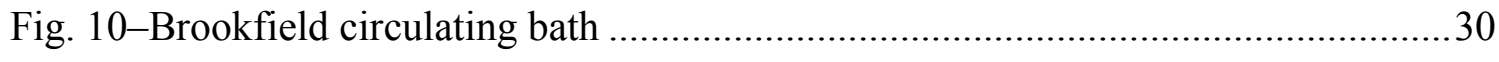

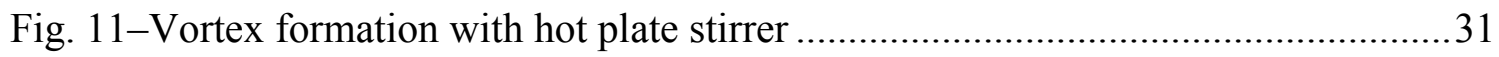

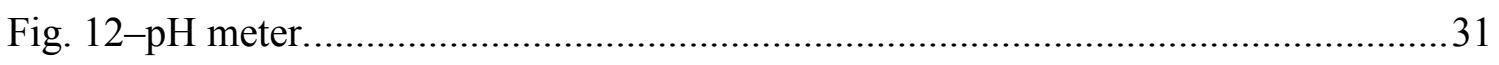

Fig. 13-HPAM/PEI gel (7000ppm/7000ppm): Different hydration techniques ..............38

Fig. 14-HPAM/PEI gel (7000ppm/5000ppm): Different hydration techniques .............39

Fig. 15-HPAM/PEI gel (7000ppm/3000ppm): Different hydration techniques .............40

Fig. 16-HPAM/PEI gel (4000ppm/4000ppm): Different hydration techniques .............41

Fig. 17 - HPAM/PEI gel (9000ppm/6000ppm): Different hydration techniques ...........42

Fig. 18 - HPAM/PEI gel (9000ppm/6000ppm): Different hydration techniques ...........43 
Fig. 19-HPAM/PEI gel (7000ppm/7000ppm): Different hydration techniques with 4wt\% $\mathrm{NaCl}$

Fig. 20-HPAM/PEI gel (7000ppm/7000ppm): Similar hydration techniques with different make up water. .46

Fig. 21-HPAM/PEI gel (7000ppm/7000ppm): Similar hydration techniques with different $\mathrm{pH}$. 47

Fig. 22-(7000ppm/70000ppm) (HPAM/PEI) Samples showing difference in pH. 48

Fig. 23-HPAM/PEI gel (7000ppm/7000ppm): Similar hydration techniques with different hydration temperature. 49

Fig. 24-HPAM/PEI gel (7000ppm/7000ppm): Similar hydration techniques with different make up water. 50

Fig. 25-HPAM/PEI gel (7000ppm/7000ppm): Pre-Gel viscosity comparison. 53

Fig. 26-HPAM/CrAc gel (4000ppm/300ppm): Pre-Gel viscosity comparison. 54 Fig. 27-HPAM/PEI gel (7000ppm/7000ppm): Viscosity behavior at ambient temperature.

Fig. 28-HPAM/CrAc gel (4000ppm/300ppm): Viscosity behavior at ambient temperature.

Fig. 29 - HPAM/CrAc gel (7000ppm/500ppm) sudden gelation @212 F 58 


\section{LIST OF TABLES}

Page

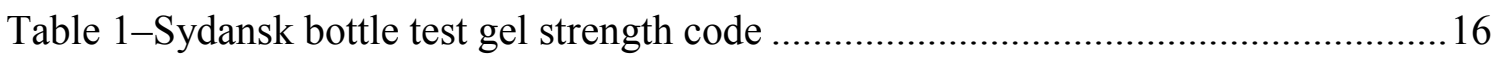

Table 2-Properties of commercial grade PEI. ......................................................... 32

Table 3- Properties of research grade PEI. .............................................................. 33

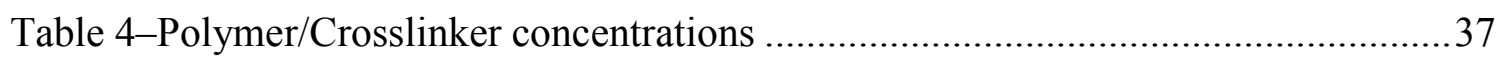

Table 5 - Gel codes for organically crosslinked gels.............................................. 51

Table 6-Gel codes for organically crosslinked gels with research grade PEI. ...............56

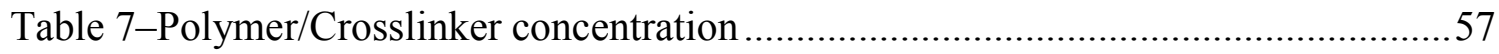

Table 8-Gel codes for inorganically crosslinked gels with fresh water........................59

Table 9-Gel codes for inorganically crosslinked gels with $4 \mathrm{wt} \% \mathrm{NaCl} \ldots \ldots \ldots \ldots \ldots \ldots \ldots . . . . . . . . .60$

Table $10-$ Gel codes for inorganically crosslinked gels with $4 \mathrm{wt} \% \mathrm{NaCl}$ hydrated at






\section{INTRODUCTION AND LITERATURE REVIEW}

\subsection{Excessive water production in petroleum reservoirs}

Water production is a serious problem during petroleum producing operations. Excessive water production becomes an issue when it competes directly with oil production. This excess water usually flows through its own pathway to the wellbore, independent of the oil flow pathway.

"On an average in the United States more than seven barrels of water are produced for each barrel of oil and worldwide, an average of three barrels of water is produced for each barrel of oil (Veil et al. 2004)." This excessive water production adds unnecessary operating expense that involves water lifting, treating, handling and disposal costs. The annual cost of disposing this water is estimated to be 5-10 billion dollars in US and around 40 billion dollars worldwide (Bailey et al. 2000).

There can be many different causes of excess water production. Problems can arise during primary oil production and can negatively impact oil recovery efficiency. Excess water production problems arise from casing leaks, water coning through matrix rock, water channeling behind pipe, fracture channeling between injection and production well and water coning through fractures (Seright et al. 2001).

This thesis follows the style of SPE Journal. 


\subsection{Types of oilfield water production}

There are two different classes of oilfield water production: Necessary and Unnecessary water production (Sydansk 2007).

Necessary water production takes place due to the fractional flow of water and oil through the matrix-rock reservoir to the production well. During a water flood in a homogenous matrix-rock reservoir, water displaces and mobilizes oil through fractional oil/water flow. Once the water breakthrough occurs at the production well, simultaneous oil/water production takes place. If necessary-water-production is shut-off, the oil production rate will also reduce. That is why reducing this necessary water production is usually not considered as an appropriate approach.

Unnecessary water production occurs when the flow of water to the production well is through a different path than the oil production pathway. There are many ways through which this water can flow to the production well. Water coning through underlying aquifers and channeling of water from the injection well to the production well through high conductive natural fractures are two such ways of unnecessary water production.

\subsection{Diagnosis of excess water production problems}

Because there are very different causes of excessive water production, these problems require different approachs to diagnose and design the best solution. "To achieve a high success rate when treating water production problems the nature of the problem must be identified correctly (Seright et al. 2001).” 
As per Seright et al. 2001 there are several reasons that exist for inadequate diagnosis of excess water production. Firstly, operators do not perform the diagnostic task of evaluating the problem due to lack to time and money. Second, there are more than 30 different diagnostic methods that can be applied and if a cost effective methodology is absent for diagnosing this problem then the operators do not perform any diagnosis. Third, operators incorrectly believe in a single solution to the problem or that only a single type of problem exists like water coning and finally the belief of service companies in single "magic-bullet" method for solving all types of problems.

A strategy to attack excessive water production is very important to avoid the mistakes mentioned above and a proposed approach should be primarily to attack the easiest problem first and secondarily the diagnosis of the water production problem should begin with the information already at hand (Seright et al. 2001).

For the proposed strategy to work one should know if the excess water production is due to leaks or flow behind pipe or is it caused by fracture or fracture like feature or is it due to matrix flow problems compounded by cross flow.

Since, this study is based on preparation of "flowing" gels (low concentration of moderately high molecular weight polymer) for treating fractured zones. Permeability reduction in fractures and non-matrix features is going to be discussed. 


\subsubsection{Excessive water production due to influx through fractures connected to} underlying water

This problem occurs when water production from an underlying aquifer is due to the connectivity of vertical fractures or similar high permeability reservoir irregularity to the wellbore as shown in Fig. 1. Though quite different from matrix coning of water from below (sometimes referred to as three-dimensional (3-D) Coning). This type of water production from a fracture connected to underlying water is often referred to as two-dimensional (2-D) coning.

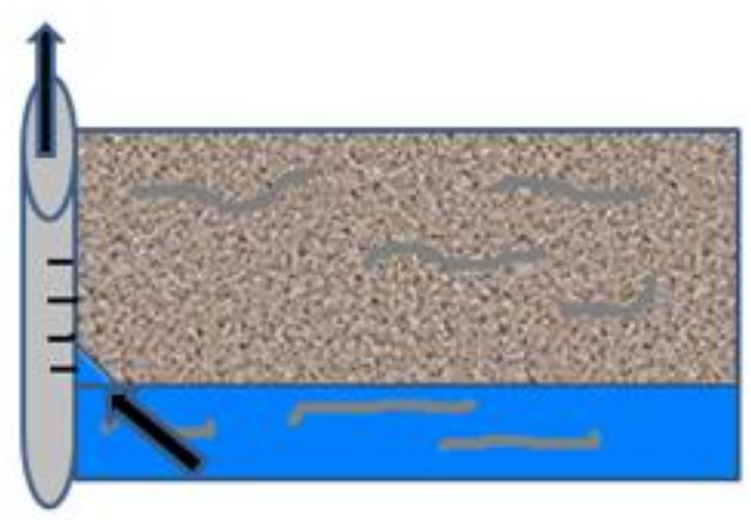

Fig. 1-Fracture network coning

\subsubsection{Excessive water production due to fracture channeling}

Excessive water production due to fracture channeling between an injector and one or more offset producer is caused during waterflood oil-recovery through a reservoir 
that possesses natural fractures connecting injector and one or more producers as shown in Fig. 2. A single well pattern may have one or up to hundreds of natural fractures.

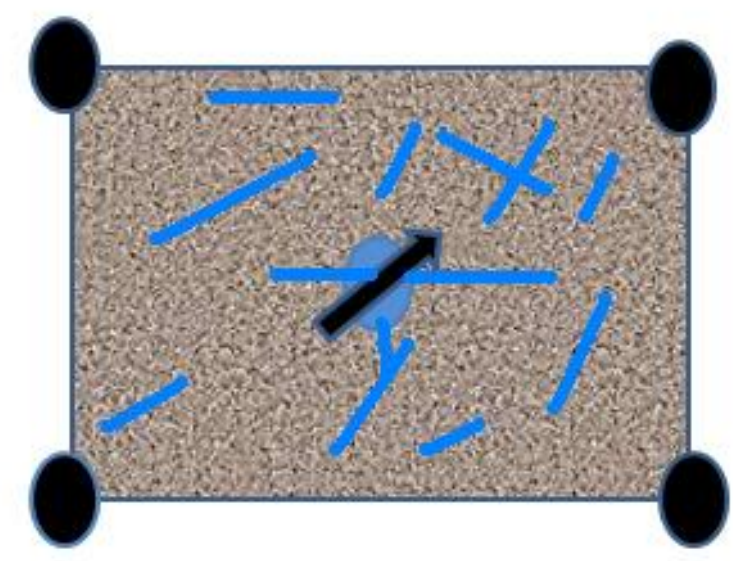

Fig. 2-Fracture channeling

\subsection{Techniques to decrease excess water production}

There are both mechanical and chemical means of decreasing excess water production. The wide array of mechanical techniques is beyond the scope of this thesis. With chemical techniques water production can be decreased by two different methods. The first is to increase the viscosity of the displacement fluid used for oil recovery. Polymer flooding is one the most used methods for increasing the viscosity of the displacement fluid.

The second technique is the placement of permeability-reducing material in the offending reservoir high permeability flow channels. This technique involves injection of permeability reducing fluid either near or far away from the wellbore region of a reservoir. The permeability reducing fluids may be pumped from either an injection well 
or a production well. Gels are used extensively in the oil and gas industry as a permeability reducing material.

Near-well treatments include those for treating such problems as casing leaks, small-aperture cement channels or matrix zone total shutoff. The gels used are often referred as "rigid" gels and are usually prepared with HPAM polymer of low molecular weight $(250-500$ thousand Daltons) at higher concentrations (5-7\% by weight). These gels are referenced here for completeness. However, they are usually applied in small volumes (up to several hundred barrels) and batch mixed. As such they are not the subject of this investigation.

Treatments designed to inhibit water influx through fractures often require placement of a gel tens to hundreds of feet beyond a wellbore. For 2-D coining, water shut-off with moderate to large volumes of polymer gels (several hundred to several thousand barrels) has proved to be very efficient. Gel systems consisting of low concentrations (up to $1-1.5 \%$ ) of moderately high molecular weight HPAM polymer (2-5 million Daltons) plus appropriate crosslinker are typically used to treat this type of problem. Such gels are often referred to as "flowing" gels because their mechanical strength is low enough to be extruded into many natural fractures even after the gelation process is well advanced.

Fracture channeling according to Sydansk and Romero-Zerón 2011 has been successfully and economically treated through the application of injection well polymer gel treatments using "flowing" gels. Usually several thousand to tens of thousands of barrel of gel are injected to treat channeling through natural-fracture networks in the 
injector's pattern. If only one producer of a pattern is affected by short-circuit of injected water from the patterns injector, then that producer may be treated rather that treating the injector.

\subsection{Gel technology}

Gels in their many forms have been one of the most effective and popular material for permeability reduction during treatment of excess water production.

It is a fluid based system to which solid like structural properties are imparted. In technical literature the term "polymer gel" as used in this study is the elastic semi-solid material that results from chemically crosslinking water soluble polymers in aqueous solution (Syndansk and Romero-Zerón 2011).

Polymer gels prepared by using HPAM polymer are the most widely applied as permeability reduction gels.

\subsubsection{Inorganically crosslinked polymer gels}

Inorganically crosslinked polymer gels the crosslinkers used are $\mathrm{Cr}^{3+}, \mathrm{Al}^{3+}$ and $\mathrm{Zr}^{4+}$. The crosslinking mechanism in these gels occurs due to the ionic bonding between the negatively charged carboxylate groups on the polymer chain and multivalent cation. The most common inorganically crosslinked gels employ CrAc as crosslinker (Sydansk 1990). HPAM/CrAc gels have very reliable gelation times at a given temperature and extensive use in the field has demonstrated their stability to well above $200^{\circ} \mathrm{F}$. Crosslinking by chromium(III) (Cr(III)) is often portrayed as in Fig. 3, but in fact the 
$\mathrm{Cr}(\mathrm{III})$ probably exists as a cluster of three $\mathrm{Cr}(\mathrm{III})$ ions in the crosslinked gel; the actual structure is probably more complex than shown in the figure below.

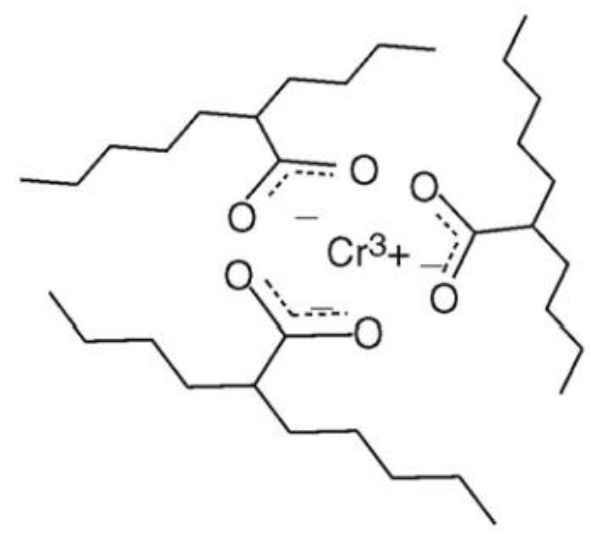

Fig. 3-Complexation of carboxylate group on polymer chains by chromium species (Reddy et al. 2003)

\subsubsection{Organically crosslinked polymer gels}

Organically crosslinked polyacrylamide gels have shown to be more stable at reservoir temperatures higher than $248^{\circ} \mathrm{F}$. A polymer gel prepared by the crosslinking mechanism between acrlyalmdie and PEI is a good example of an organically crosslinked polymer gel. The reaction mechanism between PAM and PEI is shown below in Fig. 4. 


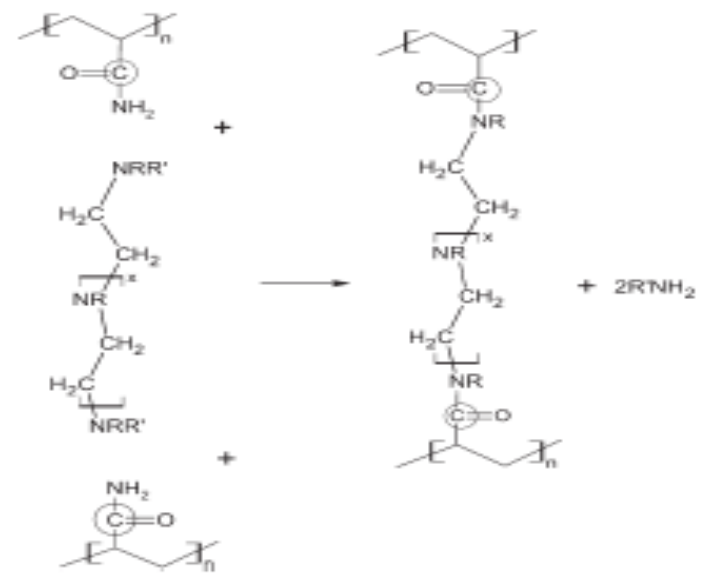

Fig. 4-Gelation mechanism between PAM and PEI (Reddy et al. 2003)

The crosslinking reaction between PEI and PAM takes place due to a substitution reaction where the nucleophilic amine nitrogen on the PEI replaced the amide groups on the polymer chan.

\subsection{Effect of lithology and oil viscosity on polymer gel}

According to a survey conducted by Seright and Liang in 1994 it was concluded that lithology can have an important impact on the success of polymer gel treatments. Most operators and vendors during that survey felt that due to the greater probability of fractures in carbonate reservoirs there was a higher success rate in these formations than others. And it was noted during this survey that most respondents felt that the specific nature of the formation was more important than the mineralogy of the rock.

In the same survey all of the respondents thought that greater success occurred in reservoirs with moderately viscous oils (Seright and Liang 1994). 


\subsection{Polymer (HPAM) handling during field operations}

There are three forms of commercial quantities of HPAM polymers for gel preparation available. These are solid, viscous solution concentrate (less than $20 \%$ by weight polymer) and "liquid" which is actually a hydrocarbon slurry of very small particles $(\sim 50 / 50 \mathrm{w} / \mathrm{w})$ that hydrate rapidly when contacted by water.

The solid grade is the lowest cost product with respect to other available forms, due in large part to lower shipping costs per unit of active polymer.

"The high molecular weight solid grade HPAM used for preparing polymer gels requires specialized wetting equipment to avoid production of blobs also known as "fisheyes" and even with the right equipment there is a learning curve period before satisfactory polymer dissolution can be accomplished routinely, during which time upsets can lead to cleanup and disposal problems (Lane 1998)." The tankage required to prepare large volumes of polymer solutions occupy a large amount of space during field applications.

The viscous solution is a true liquid concentrate which is readily diluted to final concentration, either in a batch mix or on the fly. "Mixing requires specialized but, generally, less costly equipment that the solid grade (Lane 1998)."

The liquid form which is actually slurry in a hydrocarbon carrier also contains a dispersing aid. The slurry is dispersed when injected into a flowing stream of makeup water with agitation. The blending equipment and on-the-fly mixing is similar to that used for viscous solution concentrate but with an advantage of having a higher loading of active polymer in product. For this liquid system (which is actually a form of 
emulsion polymer) any kind of accidental contact with small amounts of water or alcohols can cause them to invert to form a rigid mass that will clog equipment and flow lines.

The issue being investigated in this study is to know if optimum quality gels can be obtained by using dry polymer in a small continuous mixing system which will help in decreasing the footprint and cost of large volume flowing gel treatments.

\subsection{Rig up items for polymer placement}

The rigs up items required for the placement of polymer gels, in addition to the polymer and crosslinker blending and filtration equipment varies based on availability of makeup water and the preparation technique i.e. whether it is batch mixed or mixed onthe-fly.

For production well treatments a dissolution tank is required for makeup water or to hold batch-mixed gelant. In injection well treatments often the injection water source can be used as the makeup water for the polymer gels.

According to Lane 1998 the tankage used for the purpose of polymer hydration should be of a large enough capacity to allow a half hour or more for hydration before pumping. Thus if the pump rate is one barrel per minute (bpm), there should be at least two tanks, each with $30+$ useable barrels of capacity. As one tank is being pumped down, the other is being filled and slowly agitated to hydrate the next batch of polymer. When the first tank is emptied, the second tank is brought on line, and the first is filled again and agitated. This sequence can be repeated as many times as required for the job 
volume. Often jobs are pumped at rates of several barrels per minute, requiring correspondingly larger volumes for two or more tanks. Centrifugal pumps cannot be used to pump these gelant mixtures prepared from higher molecular weight polymer due to observed shear degradation of polymer. In order to solve this problem, gelant can be charged to high pressure positive displacement pumps by gravity feed or by positive displacement pumps.

Temperature as we will see in our experiments is a very important property that controls gelation time. In field application it is seldom possible to dictate the temperature of makeup water. However, water temperature may be an important component of both polymer hydration time and gelation time. An additional important concern with temperature is the potential impact of ambient temperature on makeup water, polymer solution of polymer plus crosslinker (gelant) solution in hoses and piping. If pumping is shut down for significant periods of time, fluids in hoses and piping may be negatively influenced by ambient temperatures. In hot environments, there would be concern for acceleration of crosslinking; in cold environments the concern would be freezing in hoses or piping.

"Rigup should be as simple as possible and the obvious reason for this is to include a smaller equipment footprint and faster rigup and rigdown times, which can help lower treatment cost (Lane 1998)." Additionally, the lower the numbers and lengths of hoses and pipes the less important are ambient temperature concerns in addition to safety (pressure, trip hazards) and complexity of rigup. 


\section{STATEMENT OF PROBLEM AND BACKGROUND THEORY}

For preparing the polymer gels for excess water shut off applications unpublished experiments and chemical intuition suggests that unless HPAM polymer is fully hydrated before addition of crosslinker, the final gel strength of the "flowing" gels (prepared from moderately high molecular weight HPAM) would be lower that the optimum mechanical strength. It is suggested so because of the hypothesis that the polymer chains need to be unfolded before proper crosslinking can occur.

A larger footprint is required for conventional polymer hydration techniques which provide lesser flexibility and often higher cost during uncertain field operations. Standard sized polymer particles in a conventional skid tank are mixed with water and pumped into an aging tank where they are combined during the 45 to 60 minutes hydration period. While one tank is aging, the other tank is supplying polymer to the injection pumps. Crosslinker is generally added on the fly upstream of the injection pumps, although other arrangements are sometimes used. Depending on the capacity of the source well, a surge tank may also be required giving us a total of three tanks: two age tanks and one surge tank. This increases storage and cost during field applications.

In this study two methods of polymer hydration and crosslinker addition were evaluated. The first method simulates the conventional method of hydration as mentioned above whereas in the second method the crosslinker was added directly after the initial wetting of the polymer. The effects of salinity, temperature, polymer/crosslinker concentration and $\mathrm{pH}$ have been studied on final gel strength. 
The second method of polymer hydration is simulating initial wetting of polymer and addition of crosslinker, all on the fly, allowing the turbulent flow created in the wellbore during pumping to assist in completion of hydration of the polymer. The turbulent flow created in the wellbore (in many pumping situations) and the approximate pumping time taken by the gelant solution to reach the desired location should allow the polymer to hydrate on the fly prior to crosslinking to form the final gel. If the final gel strength codes for both types of hydration techniques are similar then huge hydrating tanks will not be required and the polymer/crosslinker solution can both be added on the fly.

In order to determine the impact of timing of crosslinker addition to polymer gels the final gel strength code is an important factor. Rheological readings for majority of the samples were also taken to study the difference in viscosity of the two types of hydration techniques. 
These gel strengths were compared by preparing two identical polymer gel samples with similar polymer/crosslinker concentration, similar chemical and physical conditions like: $\mathrm{pH}$, makeup water salinity and hydration temperature but varying hydration techniques. Gel strengths were determined using a common qualitative coding system as shown in Table 1 below which was developed by Dr. Robert D. Sydansk.

The process of conducting the bottle gel strength code is by having approximately $10 \mathrm{~mL}$ polymer gel in $20 \mathrm{~mL}$ scintillation vials and inverting the vials to study the flow of the polymer gel. By the codes shown in Table 1 the characteristic of the flow of the final gel is assigned a code.

This study is conducted to see if there is any difference in the final gel strength code over time between the two different types of polymer gels prepared. Since, it is a visual method of analysis it is likely that two different observers will observe different gel codes. The code is designed so that two experienced observers will not differ by more than one code value. In this study, for most samples the codes were assigned and discussed with another research team member and a general consensus was achieved for determining the gel strength code for the samples prepared. 
Table 1-Sydansk bottle test gel strength code

\begin{tabular}{|c|c|}
\hline & Bottle Test Gel Strength Code \\
\hline $\mathrm{A}(1)$ & $\begin{array}{l}\text { No detectable gel formed. The gel appears to have the same viscosity } \\
\text { (fluid) as the original polymer solution and no gel is visually } \\
\text { detectable. }\end{array}$ \\
\hline $\mathrm{B}(2)$ & $\begin{array}{l}\text { Highly flowing gel. The gel appears to be only slightly more viscous } \\
\text { than the initial polymer solution. }\end{array}$ \\
\hline $\mathrm{C}(3)$ & $\begin{array}{l}\text { Flowing gel. Most of the obvious detectable gel flows to the bottle } \\
\text { cap upon inversion. }\end{array}$ \\
\hline $\mathrm{D}(4)$ & $\begin{array}{l}\text { Moderately flowing gel. A small portion (about } 5-15 \% \text { ) of the does } \\
\text { not readily flow to the bottle cap upon inversion - usually } \\
\text { characterized as a "touging" gel (i.e. after hanging out of the bottle, } \\
\text { gel can be made to flow back into the bottle by slowly turning the } \\
\text { bottle upright). }\end{array}$ \\
\hline $\mathrm{E}(5)$ & $\begin{array}{l}\text { Barely flowing gel. The gel slowly flows to the bottle cap and/ or a } \\
\text { significant portion }(>15 \%) \text { of the gel does not flow upon inversion. }\end{array}$ \\
\hline $\mathrm{F}(6)$ & $\begin{array}{l}\text { Highly deformable non flowing gel. The gel does not flow to the } \\
\text { bottle cap upon inversion (gel flows to just short of reaching the bottle } \\
\text { cap). }\end{array}$ \\
\hline $\mathrm{G}(7)$ & $\begin{array}{l}\text { Moderately deformable non-flowing gel. The gel flows about halfway } \\
\text { down the bottle upon inversion. }\end{array}$ \\
\hline $\mathrm{H}(8)$ & $\begin{array}{l}\text { Slightly deformable non-flowing gel. Only the gel surface deforms } \\
\text { slightly upon inversion. }\end{array}$ \\
\hline $\mathrm{I}(9)$ & Rigid gel. There is no gel surface deformation upon inversion. \\
\hline $\mathrm{J}(10)$ & $\begin{array}{l}\text { Ringing rigid gel. A tuning-fork like mechanical vibration can be felt } \\
\text { after the bottle is tapped. }\end{array}$ \\
\hline
\end{tabular}




\subsection{Viscosity}

Viscosity is also an important factor for understanding the flow behavior of the prepared gels. The rheological behavior of these polymer gels will be useful while designing pumping and piping systems.

Viscosity of HPAM solutions decreases with increasing salinity and hardness. The reduction in viscosity of solutions of HPAM by salt is caused by the association of cations with the negative charger along the polymer chain (Ward and Martin 1980). This association screens the charges and prevents the repulsion which normally gives the polymer its extended configuration with very large hydrodynamic volume.

The most sensitive method for material characterization is rheology because flow behavior is responsive to properties such as molecular weight and molecular weight distribution. Rheological measurement will also show us the course of chemical, mechanical and thermal treatments.

Viscosity is the measure of the internal friction of a fluid. The greater the friction, the greater the amount of force required to cause this movement, which is called "shear". Isaac Newton defined viscosity by considering the following model where two parallel flat areas " $A$ " area were separated by a distance of " $\mathrm{dx}$ " which are moving in the same direction at different velocities "V1" and "V2." Newton assumed that the force required to maintain this difference in speed was proportional to the difference in speed through the liquid which he expressed as:

$$
\frac{F}{A}=\eta \frac{d v}{d x}
$$


where $\eta$ for a given material is a constant called viscosity and its fundamental unit of is "poise."

The velocity gradient $\frac{d v}{d x}$ is a measure of the change in speed at which the intermediate layers move with respect to each other. It describes the shear rate and is also symbolized as "S" and its unit of measure is "reciprocal second" $\left(\sec ^{-1}\right)$. The term F/A indicates the force per unit area required to produce the shearing action referred as "shear stress" and its unit of measurement is "dynes per square centimeter" $\left(\right.$ dynes $\left./ \mathrm{cm}^{2}\right)$.

Flow behavior of fluids can be characterized by Newtonian and Non-Newtonian fluids.

Newtonian Fluids - Are those fluids whose viscosity with remain constant at a given temperature regardless of which Viscometer spindle or speed one measures it with. The graph in Fig. 5 below shows the relationship between viscosity $(\eta)$ and shear rate $\left(F^{\prime}\right)$ as a straight line and viscosity $(\eta)$ remains constant as shear rate is varied. 


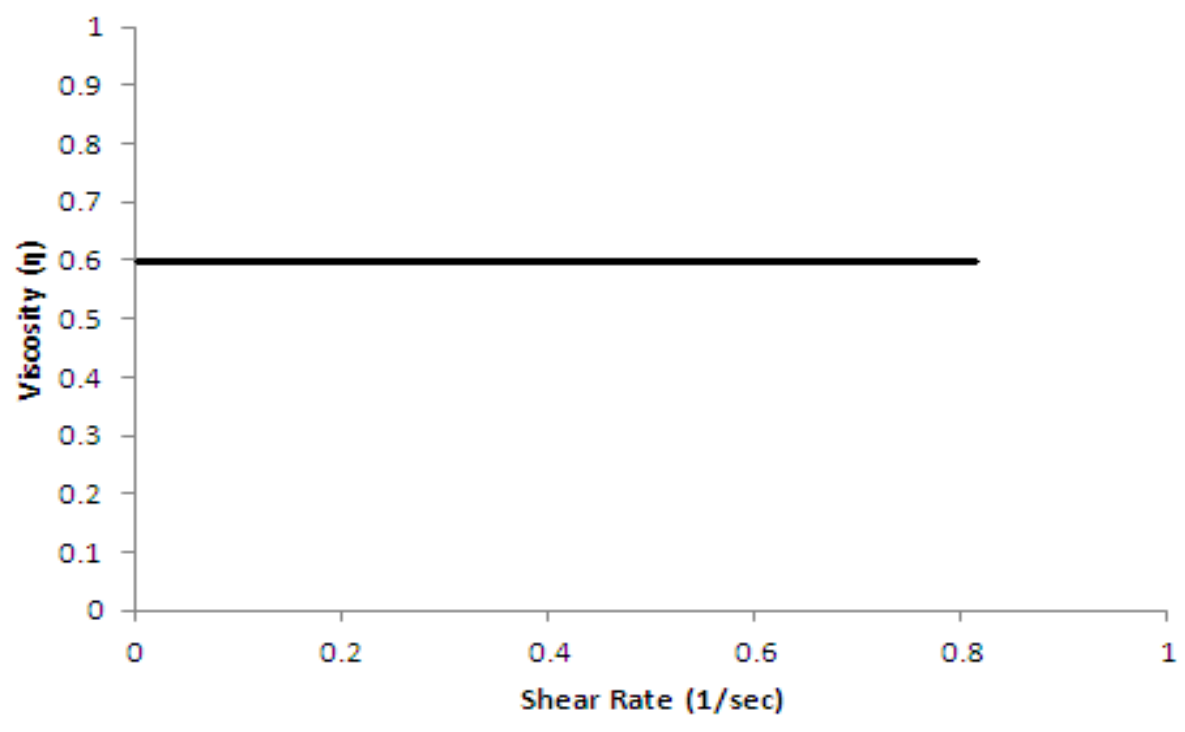

Fig. 5-Newtonian fluid behavior

Non- Newtonian fluids - Are those fluids whose viscosity is not constant when shear rate is varied. In other words the shear stress does not vary in the same proportion or even in the same direction as the shear rate. There are many types of non-Newtonian flow behavior characterized by the way a fluids viscosity changes in response to variations in shear rate. Some of the common types are:

1) Pseudoplastic - Are fluids whose viscosity decreases with increasing shear rate. This type of behavior is called "shear-thinning" and its behavior is shown in Fig. 6 below. The polymer gels prepared in the following experiments show a pseudo plastic behavior. 


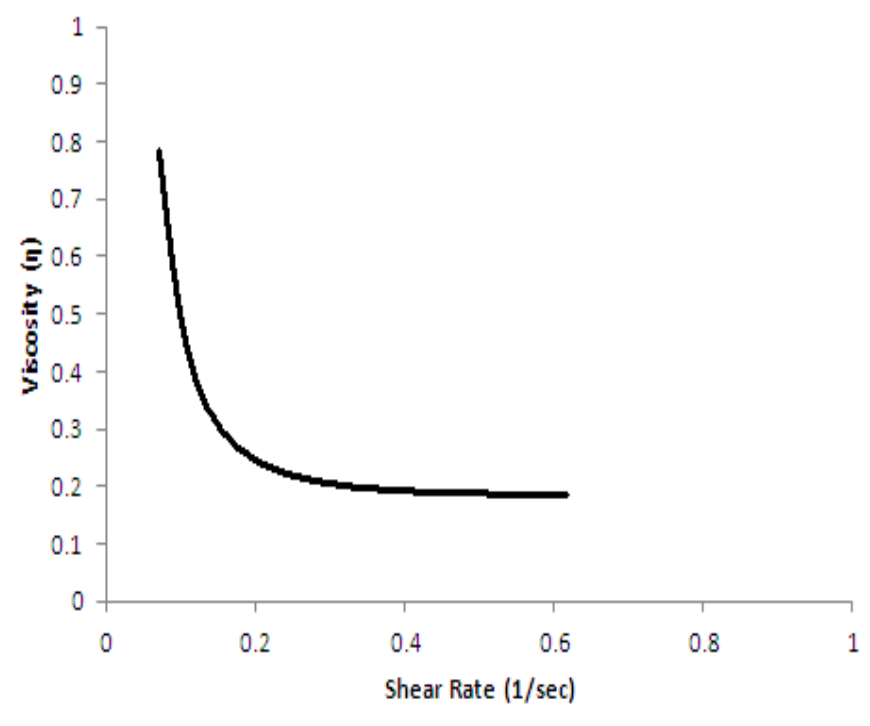

Fig. 6-Non-Newtonian fluid behavior

\subsection{Effect of laminar and turbulent flow}

The definition of viscosity implies the presence of "laminar flow" which is the movement of one layer of fluid past another with no transfer of matter from one to the other and viscosity will be the friction between these layers.

There is also a certain maximum speed at which one layer of fluid can move with relation to another, beyond which an actual transfer of mass occurs which is "turbulent flow." In this flow molecules will jump from one layer to another and dissipate a substantial amount of energy which causes a larger energy input required to maintain than laminar flow at same velocity giving us an erroneously high viscosity reading. 


\subsection{Importance of gelation time}

The inflection point on the viscosity vs. time curves is defined as gelation time.

Gelation time controls the volume of fluid that can be injected in the treatment and thus is an important variable during water shutoff applications. The "flowing" gels studied here and the reason we call them "flowing" gels is that they can still be pumped after gelation has occurred.

In our experiments the gelation time is a good indicator of the crosslinking mechanism taking place during both types of hydration techniques, especially when conditions like $\mathrm{pH}$, salinity and temperature are varied. Since, we are comparing the final viscosities of gels formed after initial wetting of polymer particles to completely hydrated polymer solution we want the gelation time in the former case to be longer than the hydration time for the polymer which is approximately 30 minutes.

\subsection{Behavior of organically crosslinked polymer gels}

\subsubsection{Effect of temperature on HPAM/PEI polymer gels}

Temperature is an important factor for polymer gels used for water shut off as it strongly affects the gelation time. As per studies conducted by Al-Muntasheri et al. 2007, it has been found that for a HPAM/PEI system the gelation time decreases with increasing temperature, indicating an endothermic type of reaction (Nasr-El-Din and Taylor 2005). In order to delay gelation time while pumping this type of polymer gel 
system, a preflush would decrease the temperature near the wellbore. The gelation time and temperature were correlated according to an Arrhenius-type equation:

$$
\mathrm{GT}=\mathrm{M} \exp \left(\mathrm{E}_{\mathrm{a}} / \mathrm{RT}\right)
$$

where GT is the gelation time in seconds, Ea is the activation energy in $\mathrm{kj} / \mathrm{mol}, \mathrm{R}$ is the universal gas constant and $\mathrm{T}$ is the absolute temperature in Kelvin.

\subsubsection{Effect of salinity on HPAM/PEI polymer gels}

HPAM polymers are highly sensitive to salinity based environments. The gelation time increases with increasing salinity in the makeup water. This is due to the production of carboxylate groups carrying negative charges under high $\mathrm{pH}$ conditions which stretches the HPAM network increasing the hydrodynamic volume of the polymer. The sodium plus the chloride ions screen the positive PEI from negative HPAM causing contraction of HPAM coils which increases the induction period causing longer gelation times (Nasr-El-Din et al. 1991).

\subsubsection{Effect of polymer concentration on HPAM/PEI polymer gels}

According to a study conducted by Al-Muntasheri et al 2007 the gelation time can be decreased by using higher polymer concentrations and vice versa. Lower polymer concentration lead to formation of weaker gels therefore it is important to examine the gel strength as a function of composition prior to field application in high temperature environment. 


\subsubsection{Effect of pH on HPAM/PEI polymer gels}

Previous studies suggest that at lower $\mathrm{pH}$ values the gelation time increases. This behavior is because in acidic medium the lone pair of electrons on the amine nitrogen's are expected to be protonated which makes them unavailable to initiate a nucleophilic attack on the amide carbonyl group of the base polymer (Reddy et al. 2003).

\subsection{Behavior of HPAM/CrAc polymer gels}

According to bottle tests conducted by Sydansk 1990 the HPAM/CrAc gel formulations were studied over a wide range of chemical formulations, and temperatures. Bottle testing was also used to determine trends caused by varying gel parameters like polymer and crosslinker concentration, temperature, salinity, and $\mathrm{pH}$.

Gel strength tends to increase with increasing $\mathrm{Cr}(\mathrm{III})$ content and increasing HPAM polymer concentrations. Gel strength is favored by an alkaline $\mathrm{pH}$ which according to Sydansk 1990 is in contrast to many commercial oilfield acrylamidepolymer gels where gelation is favored by acidic $\mathrm{pH}$.

"Gels applicable for high temperature use (up to $255^{\circ} \mathrm{F}$ ) are more restricted in their formulations and more sensitive to salinity and hardness, which also reduces the range of polymer to $\mathrm{Cr}$ (III) ratios over which stable gels are formed(Sydansk1990)." 


\subsection{Viscosity readings}

A Brookfield Viscometer was used to take the viscosity reading with varying temperatures. The torque required to rotate an immersed element in a fluid is measured. A motor drives the spindle through a calibrated spring and the deflection of the spring is indicated by a digital display. Multiple speed transmission and interchangeable spindles when utilized can provide a variety of viscosity ranges that can be measured.

For a given viscosity, the viscous drag, or resistance to flow (indicated by the degree to which the spring winds up), is proportional to the spindles speed of rotation and is related to the spindle's size and shape. The drag will increase as the spindle size or rotational speed increases. It follows that for a given spindle geometry and speed, an increase in viscosity will be indicated by an increase in deflection of the spring. Measurement made using the same spindles at different speeds are used to detect and evaluate rheological properties of the test fluid.

The Viscometer is composed of several mechanical subassemblies. The schematic view of the major components of a basic dial-reading Viscometer can be seen in Fig. 7. 


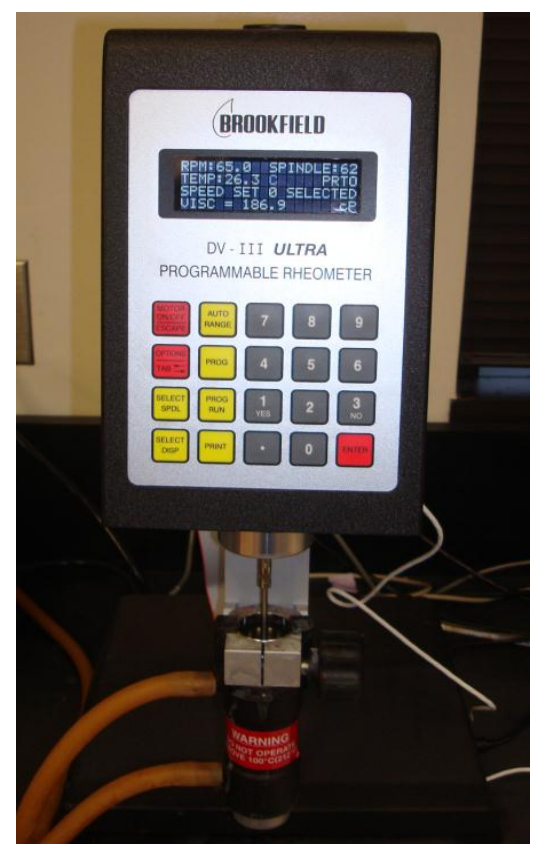

Fig. 7-Brookfield viscometer

At the top of the instrument, housed inside the area where the nameplate is attached the stepper drive motor is located. A calibrated beryllium-copper spring is contained in the viscometer main case, one end of which is attached to the pivot shaft; the other end is connected directly to the dial. A motor drive shaft drives this dial which through the calibrated spring drives the pivot shaft.

During the dial-reading models the angular position in relation to the dial is indicated by the pointer connected to the pivot shaft. And in the digital models the relative angular position of the pivot shaft is detected by a rotary variable displacement transducer which displays it on the digital meter.

The lower end of the pivot shaft protrudes through the pivot cup which is below the main case. A jewel bearing inside the pivot cup rotates with the dial and the pivot 
shaft is supported on this bearing by the pivot point. The spindle coupling is present at the lower end of the pivot shaft to which the Viscometer's spindles are attached (Brookfield Engineering Laboratories).

\subsection{Selecting a spindle speed}

The best method for spindle and speed selection is trial and error while conducting an original test. The goal is to obtain a Viscometer dial or display (\% torque) reading between 10 and 100 . If the reading is over 100 a slower speed or a smaller spindle is selected. Conversely, if the reading is under 10, a higher speed or a larger spindle is selected.

For conducting these experiments a standard disc-type spindle was used as shown in Fig. 8. The following figure shows the Brookfield container used for holding the polymer gel and the disc type spindle used for shearing the gel. 


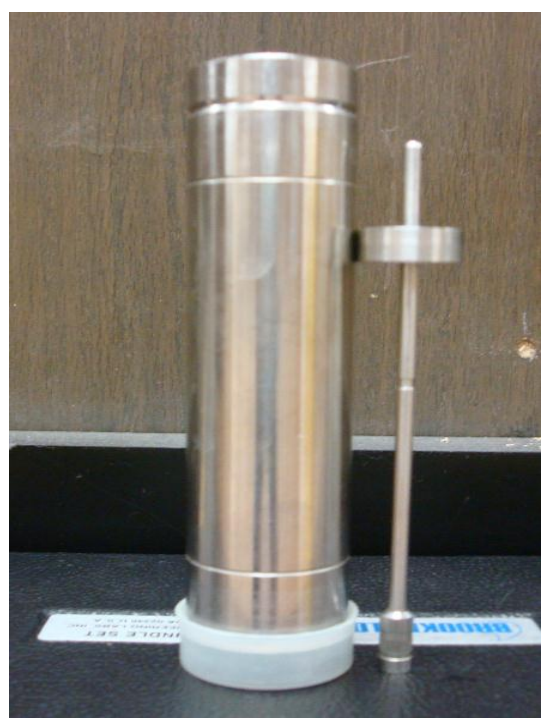

Fig. 8-Brookfield gel holder and disc spindle

\subsection{Data collection plan}

After taking the viscosity readings for the desired polymer gel solutions, gel strength codes were noted over time by placing the samples in a $200{ }^{\circ} \mathrm{F}$ oven. The Fig. 9 below provides the experimental data collection plan.

As you can see the main difference is the type of hydration techniques after which rest properties are kept similar for respective runs. 


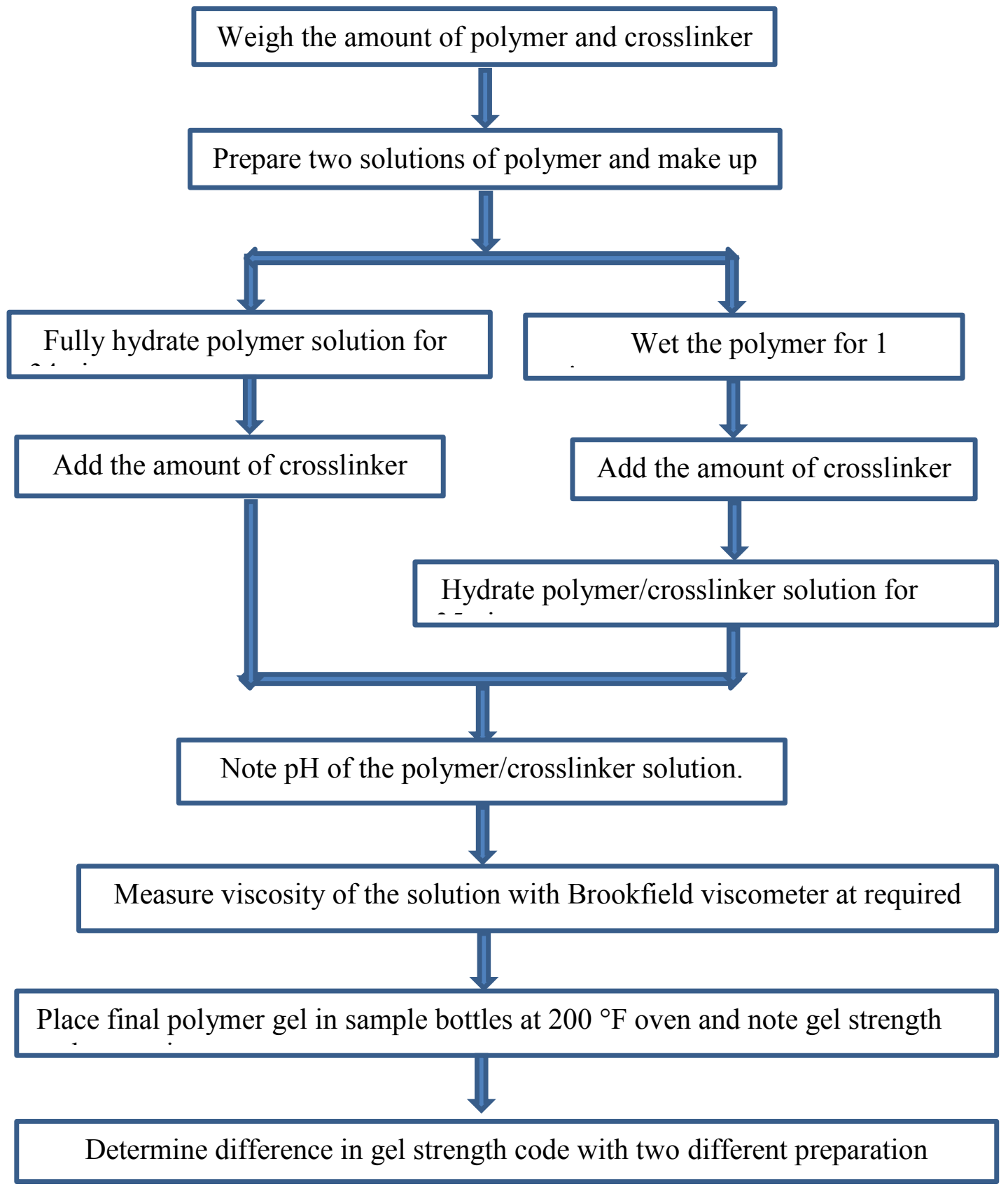

Fig. 9-Flowchart: Data collection 


\section{EXPERIMENTAL PROCEDURE AND EQUIPMENT}

The final gel strengths were determined by studying the variation in polymer/crosslinker concentration, $\mathrm{pH}$, and salinity and hydration temperature. The goal of this study to determine whether there is any difference in final gel strength code of polymer gels developed by two different types of hydration techniques i.e. initially hydrated polymer solution and completely hydrated polymer solution. The rheological behavior of majority gelant solutions was also studied to observe differences in their gelation times with the help of a Brookfield viscometer. The gelation time for the conducted experiments was noted when there was an inflection in the viscosity. In some cases there was a sharp inflection and in others a more gradual one. Once the gelant solution reached a final viscosity of $400 \mathrm{cP}$, it was contained in scintillation vials which were placed in an oven at $200^{\circ} \mathrm{F}$. These samples were then allowed to age and gel strength codes were noted overtime. The final viscosity of $400 \mathrm{cP}$ mentioned here is an arbitrary value and should not be considered as the point of complete gelation as the time taken would be much longer.

The crosslinker bears the most cost of a polymer gel as the solid grade HPAM in these experiments is much cheaper. So, a robust gel with minimum crosslinker concentration would be the best fit for utilization.

\subsection{Equipment used}

1) Brookfield viscometer - This device was used to study the viscosity of the polymer gels over time. 
2) Brookfield Circulating Bath - As seen in Fig. 10 this equipment was used to adjust the temperature of the polymer gel container while taking viscosity readings.

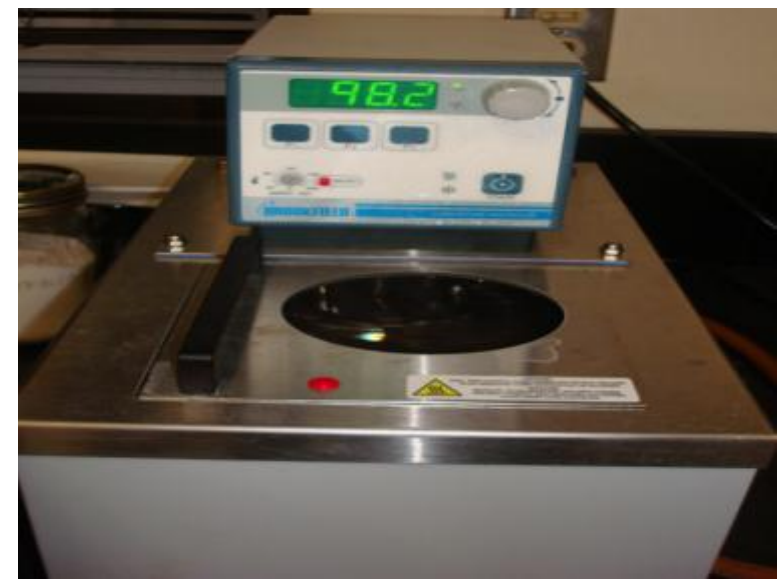

Fig. 10-Brookfield circulating bath

3) Hot Plate Stirrer - A hot plate stirrer as shown in Fig. 11 was used for hydrating the polymer at a higher temperature and at ambient temperature. It is crucial to maintain a vortex while polymer addition in order to avoid the creation of blobs known as "fisheyes". 


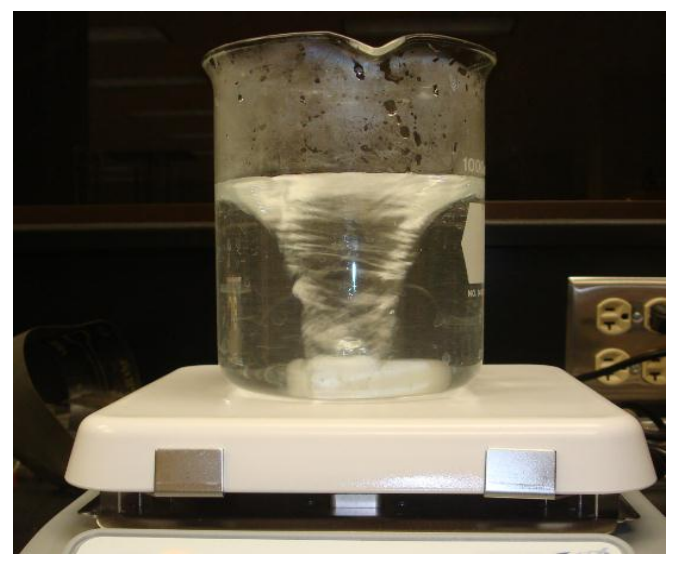

Fig. 11-Vortex formation with hot plate stirrer

4) $\mathrm{pH}$ meter- $\mathrm{A} \mathrm{pH}$ meter as seen in Fig. 12 from Orion Star was used to determine the $\mathrm{pH}$ after the final polymer/crosslinker solution was ready for viscosity readings.

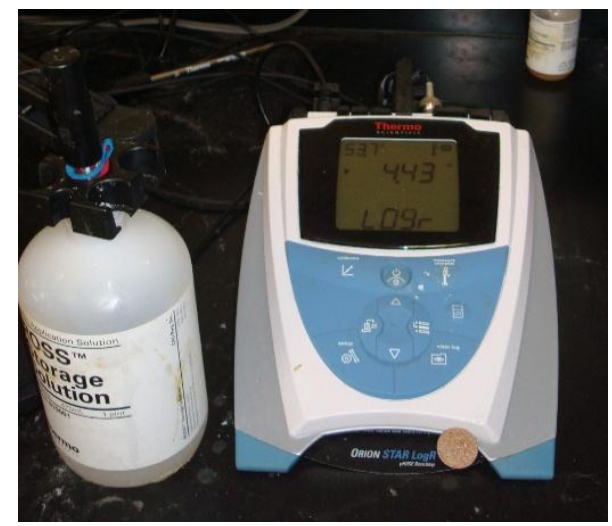

Fig. 12-pH meter. 


\subsection{Material used for conducting experiments}

1) Polymer - A high molecular weight, solid grade HPAM in the range of 2,00,000 $5,00,000 \mathrm{Da}$ was used as a polymer.

2) Commercial grade organic crosslinker - PEI

The properties of the commercial grade organic crosslinker used can be seen in

Table. 2 .

Table 2-Properties of commercial grade PEl.

\begin{tabular}{|c|c|}
\hline \multicolumn{2}{|c|}{ Commercial Grade Organic Crosslinker } \\
\hline Physical Form & Liquid \\
\hline Molecular weight & $500,000-1,200,000 \mathrm{Da}$ \\
\hline Color & Yellow to Brown \\
\hline Odor & Slight \\
\hline pH & -8 at $50 \mathrm{~g} / \mathrm{L}$ \\
\hline Freezing Point & $100^{\circ} \mathrm{C}\left(212^{\circ} \mathrm{F}\right)$ at $1,013 \mathrm{hPa}$ \\
\hline Boiling Point & 1.06 \\
\hline Specific Gravity & $150-350 \mathrm{mPa} . \mathrm{s}$ at $23{ }^{\circ} \mathrm{C}\left(73.4^{\circ} \mathrm{F}\right)$ \\
\hline Dynamic Viscosity & $\mathrm{USD}^{\circ} / \mathrm{lb}$ \\
\hline Cost & \\
\hline
\end{tabular}




\section{3) Research Grade PEI}

The properties of the research grade PEI used can be seen in Table 3 .

Table 3- Properties of research grade PEI.

\begin{tabular}{|c|c|}
\hline \multicolumn{2}{|c|}{ Research Grade Organic Crosslinker } \\
\hline Physical Form & $50 \%(\mathrm{w} / \mathrm{v})$ aqueous solution \\
\hline Molecular weight & $50,000-1,00,000$ (Average) \\
\hline Color & Colorless to light yellow \\
\hline $\mathrm{pH}$ & Approximately $10.5-11.0$ \\
\hline Density & $1.07 \mathrm{~g} / \mathrm{ml}$ \\
\hline Viscosity & $\left(20^{\circ} \mathrm{C}, 20 \mathrm{rpm}\right) 10,000-20,000 \mathrm{cp}$ \\
\hline
\end{tabular}

4) Inorganic Crosslinker - Chromium(III) Acetate.

\subsection{Viscosity behavior}

The viscosity behavior shown for certain polymer and crosslinker concentration is based on reproduced results which were carried out at $212^{\circ} \mathrm{F}$. The $\mathrm{pH}$ of the PEI was increased by the addition of a few drops on $1 \mathrm{~N} \mathrm{NaOH}$ due to the presence of certain impurities in the received liquid PEI. These impurities were unknown through the course of the experiments due to the trade secret by the supplier company. The effect of salinity 
was studied by using fresh water and $4 \mathrm{wt} \% \mathrm{NaCl}$ water for polymer hydration. The difference in hydration behavior was also studied by using a hot plate stirrer.

\subsection{Experimental procedure}

The experimental method can be broken down into three different parts:

1) Polymer/crosslinker solution preparation

2) Viscosity Measurement

3) Determining gel strength code.

A detailed description of the experimental procedure is given below:

\subsubsection{Polymer/Crosslinker solution preparation}

The polymer concentration used in the following experiments was in the range of 4000 - 7000 parts per million (ppm). Two samples were prepared for studying the effect of crosslinker addition at different intervals.

\section{For testing crosslinker addition to fully hydrated polymer}

1) Weigh the appropriate amount of polymer on the digital weighing balance.

2) Prepare a $100 \mathrm{~mL}$ solution of polymer and crosslinker, adding the polymer to the vortex of an already stirring water container on a magnetic stirrer.

3) A hot plate stirrer was also used where the polymer hydration was conducted at a higher temperature.

4) After full hydration of polymer, which is performed over 35 mins crosslinker is added to the polymer solution and stirred for 5 mins. 
5) The $\mathrm{pH}$ of the polymer/crosslinker solution was noted before placing the fluid in the Brookfield container which was set up at the testing temperature with the help of a circulating bath.

\section{For testing crosslinker addition in wetted but not fully hydrated polymer}

1) Weigh the appropriate amount of polymer on the digital weighing balance.

2) Prepare a $100 \mathrm{~mL}$ make up water and add the polymer to the vortex of an already stirring water container on a magnetic stirrer.

3) A hot plate stirrer was also used where the polymer hydration was conducted at a higher temperature.

4) After wetting the polymer for 1 min crosslinker was added to the polymer solution and stirred for 39 mins, keeping the total time similar to that of the other sample.

5) The $\mathrm{pH}$ of the polymer/crosslinker solution was noted before placing the fluid in the Brookfield container which was set up at the testing temperature with the help of a circulating bath.

\subsubsection{Viscosity measurements}

6) A disc spindle was selected and an rpm of 65 was selected for all experiments to keep the torque $\%$ between $10-100$ for correct readings. 
7) The readings from the viscometer were taken in every five minutes until gelation time or in some cases the final viscosity remained constant for a long period of time.

\subsubsection{Determining gel strength code}

8) After the viscosity readings were taken the polymer gel samples were contained in a $20 \mathrm{~mL}$ bottle and placed in a preheated oven at $200^{\circ} \mathrm{F}$.

9) A bottle test method otherwise known as Sydansk bottle test method was used to determine the gel strength over time. 


\section{RESULTS AND INTERPRETATION}

\subsection{Organically crosslinked gels - Hydrated at ambient temperature}

For these types of polymer gels PEI was used as a crosslinker and a high molecular weight HPAM as the polymer. Since the PEI was in liquid form and $25 \mathrm{wt} \%$ active, calculations were made which resulted in the following Table 4 for polymer/crosslinker concentrations.

Table 4-Polymer/Crosslinker concentrations

\begin{tabular}{|c|c|c|c|}
\hline HPAM $(\mathrm{ppm})$ & HPAM $(\mathrm{g} / 100 \mathrm{~mL})$ & PEI $(\mathrm{ppm})$ & PEI $(\mathrm{mL} / 100 \mathrm{~mL})$ \\
\hline 7000 & 0.7 & 7000 & 2.857 \\
\hline 6000 & 0.6 & 6000 & 2.448 \\
\hline 5000 & 0.5 & 5000 & 2.04 \\
\hline 4000 & 0.4 & 4000 & 1.632 \\
\hline 3000 & 0.3 & 3000 & 1.224 \\
\hline
\end{tabular}

\subsection{HPAM/PEI gel (7000ppm/7000ppm)}

Fig. 13 below shows the viscosity behavior of and organically crosslinked HPAM/PEI gel. The final $\mathrm{pH}$ of the fully hydrated polymer and the partially hydrated polymer was 11.26 and 11.45 respectively. We can see that there is a certain delay in gelation time in the case of partially hydrated polymer gelant sample, which is quite consistent for HPAM/PEI gelant solutions in the experiments conducted. After placement of the final polymer gel in a $200^{\circ} \mathrm{F}$ oven for a period of 14 days the final gel strength code for the fully hydrated polymer was an $\mathrm{H}$ whereas for the partially hydrated 
polymer was a $\mathrm{G}$, a difference of one gel strength code unit between the two hydration methods.

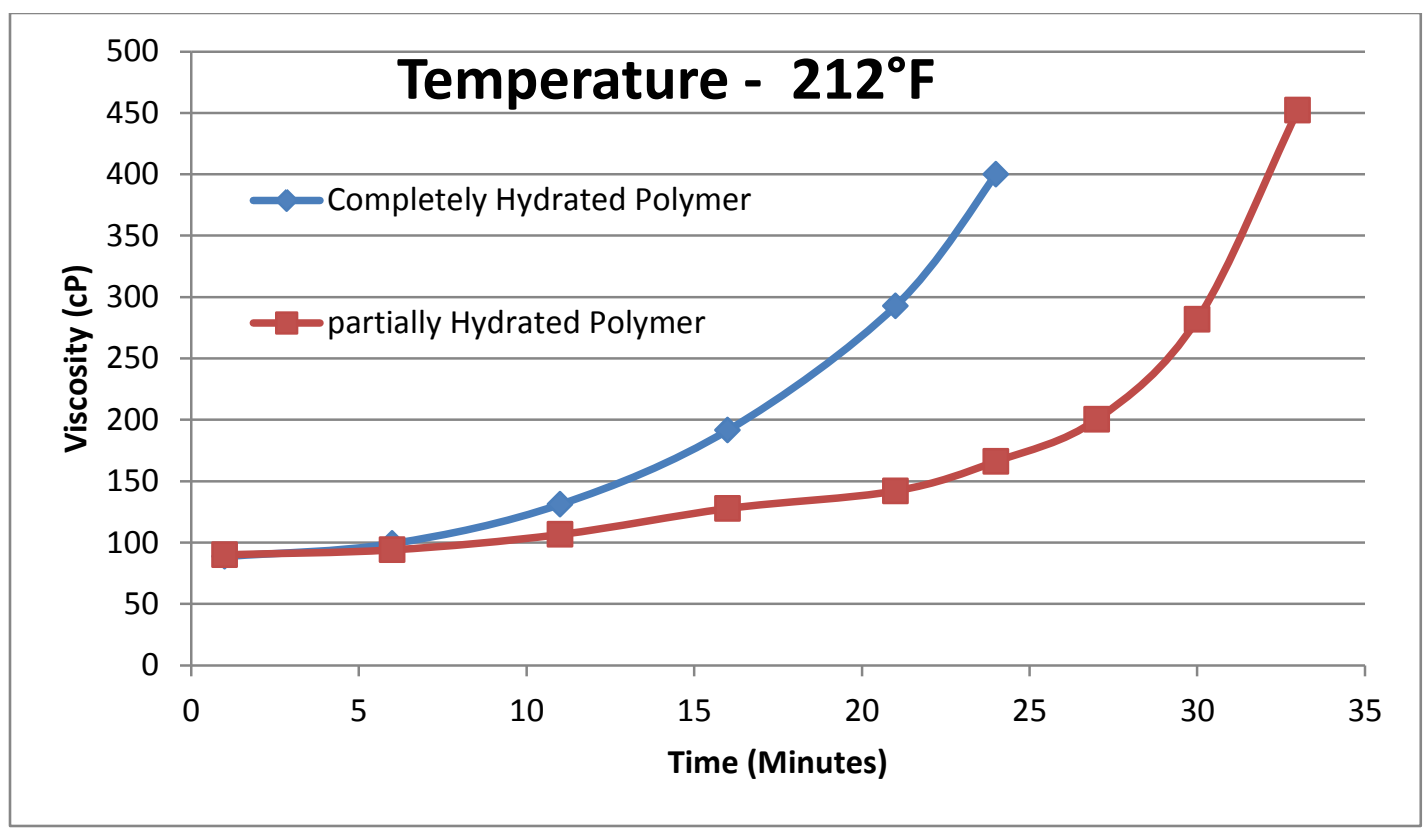

Fig. 13-HPAM/PEI gel (7000ppm/7000ppm): Different hydration techniques

\subsection{HPAM/PEI gel (7000ppm/5000ppm)}

According to the viscosity behavior of a $7000 \mathrm{ppm} / 5000 \mathrm{ppm}$ organically crosslinker gel shown in Fig. 14 we can also see that there is a certain delay in the partially hydrated polymer gelant sample to reach gelation time. The final $\mathrm{pH}$ of the fully hydrated polymer and the partially hydrated polymer was 11.33 and 11.63 respectively. After placement of the final polymer gel in a $200{ }^{\circ} \mathrm{F}$ oven for a period of 14 days the final gel strength code for the fully hydrated polymer was $G$ and the partially hydrated polymer was a F, a difference of one gel strength code unit. 


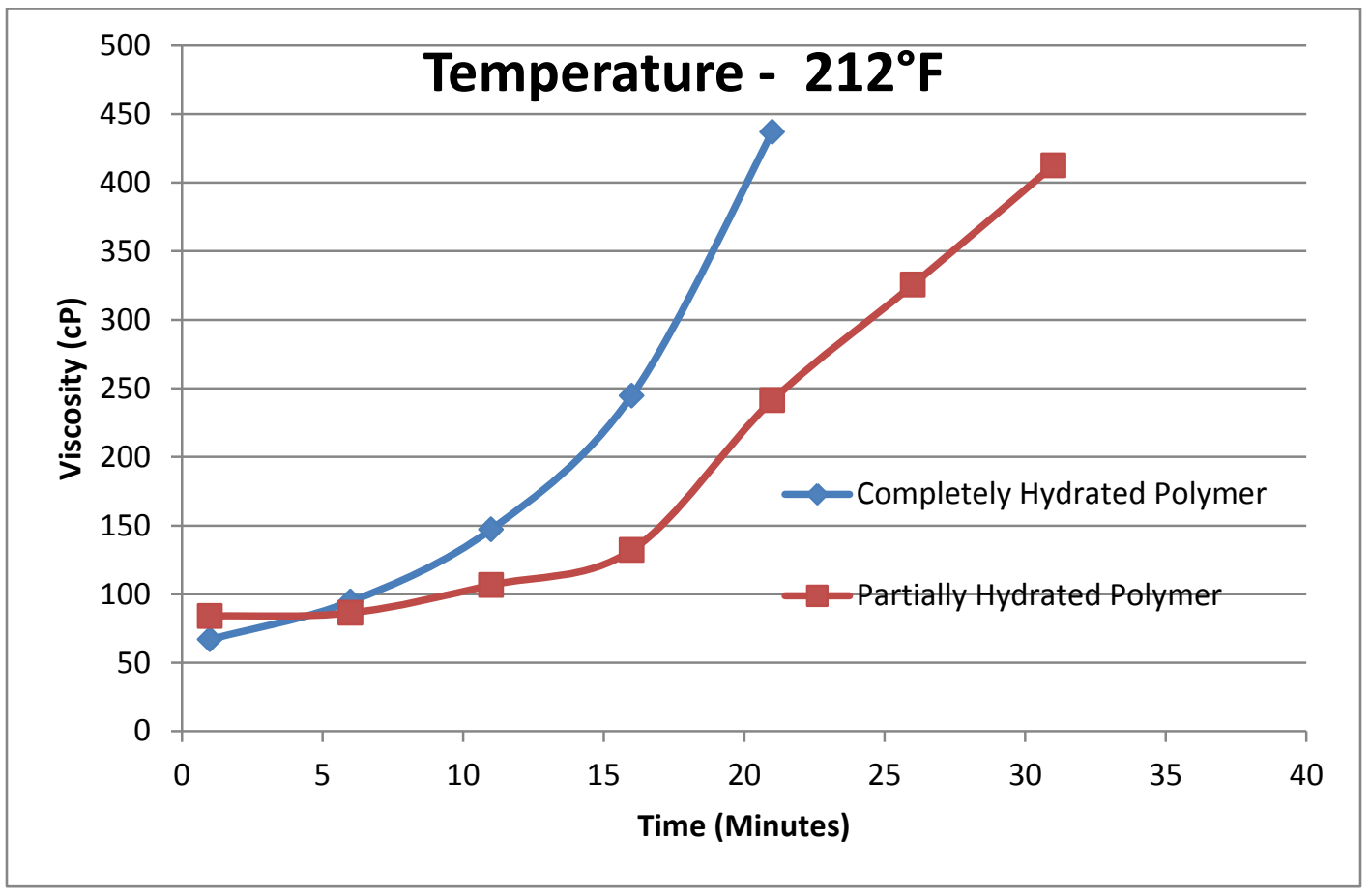

Fig. 14-HPAM/PEI gel (7000ppm/5000ppm): Different hydration techniques

\subsection{HPAM/PEI gel (7000ppm/3000ppm)}

As seen in the Fig. 15 below the time taken by the $7000 \mathrm{ppm} / 3000 \mathrm{ppm}$ organically crosslinked gel is longer. The final $\mathrm{pH}$ of the fully hydrated polymer and the partially hydrated polymer was 11.49 and 11.69 respectively. After placement of the final polymer gel in a $200{ }^{\circ} \mathrm{F}$ oven for a period of 14 days the final gel strength code for the fully hydrated polymer was a $\mathrm{G}$ whereas for the partially hydrated polymer was an E. 


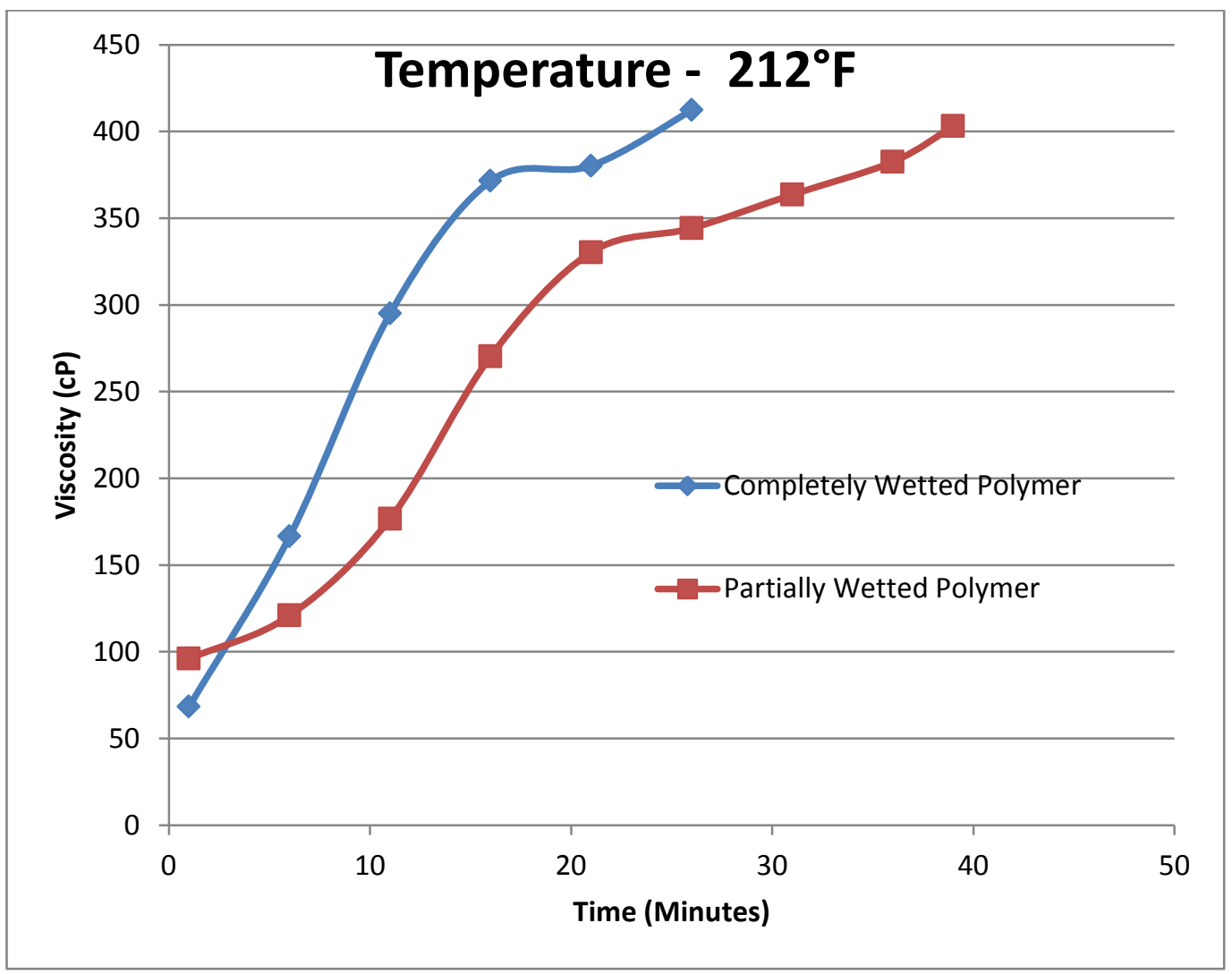

Fig. 15-HPAM/PEI gel (7000ppm/3000ppm): Different hydration techniques

\subsection{HPAM/PEI gel (4000ppm/4000ppm)}

As seen in the Fig. 16 below the time taken by the $4000 \mathrm{ppm} / 4000 \mathrm{ppm}$ organically crosslinked gel was much longer than the earlier 7000ppm polymer concentrations shown. The final $\mathrm{pH}$ of the fully hydrated polymer and the partially hydrated polymer was 9.86 and 9.82 respectively because the $\mathrm{pH}$ of the crosslinker was adjusted. After placement of the final polymer gel in a $200^{\circ} \mathrm{F}$ oven for a period of 14 days the final gel strength code for the fully hydrated polymer and the partially hydrated 
polymer was a $\mathrm{C}$. This results proves that higher polymer/crosslinker concentrations give stronger gels with faster gelation times.

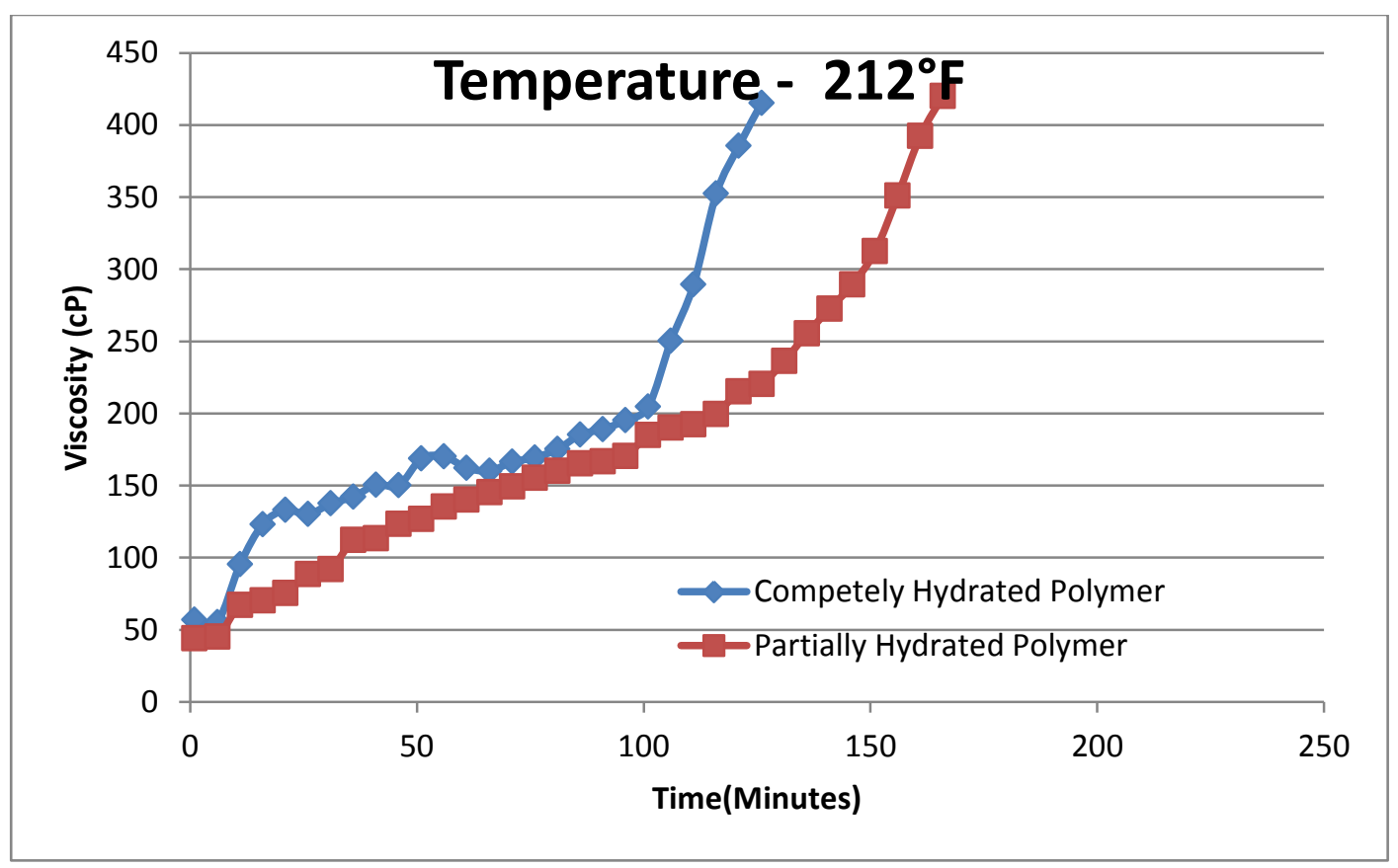

Fig. 16-HPAM/PEI gel (4000ppm/4000ppm): Different hydration techniques

\subsection{HPAM/PEI gel (9000ppm/6000ppm)}

According to the rheological behavior as seen in Fig. 17 of a $9000 \mathrm{ppm} / 6000 \mathrm{ppm}$ HPAM/PEI system we can see a faster gelation time. This also shows how high polymer loading can decrease gelation time with appropriate crosslinker concentration. The final $\mathrm{pH}$ of the fully hydrated polymer and the partially hydrated polymer was 10.67 and 10.62 respectively. After placement of the final polymer gel in a $200{ }^{\circ} \mathrm{F}$ oven for a 
period of 14 days the final gel strength code for the fully hydrated polymer and the partially hydrated polymer was identical at $\mathrm{H}$.

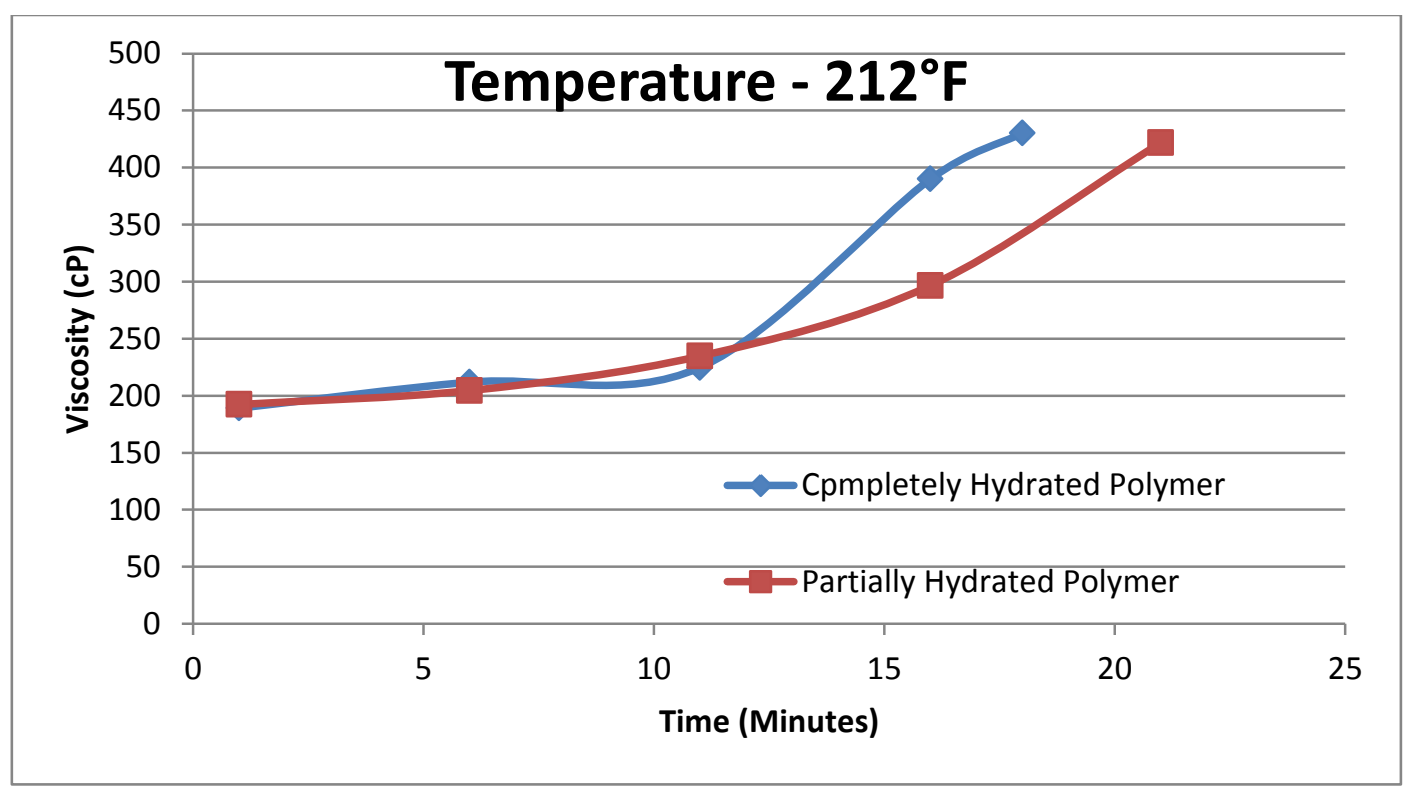

Fig. 17 - HPAM/PEI gel (9000ppm/6000ppm): Different hydration techniques

\subsection{HPAM/PEI gel (9000ppm/6000ppm): Hydrated at $122{ }^{\circ} \mathrm{F}$}

In Fig. 18 below the two different types of hydration techniques have been performed at $122^{\circ} \mathrm{F}$. The gelation time has decreased by a few minutes because of the hydration taking place at a higher temperature proving that gelation time decreases with increasing temperature. But the final gel strength code was similar to the gels prepared at ambient temperature. The final $\mathrm{pH}$ of the fully hydrated polymer and the partially hydrated polymer was 10.59 and 10.11 respectively. After placement of the final 
polymer gel in a $200^{\circ} \mathrm{F}$ oven for a period of 14 days the final gel strength code for the fully hydrated polymer and the partially hydrated polymer was i.e. H.

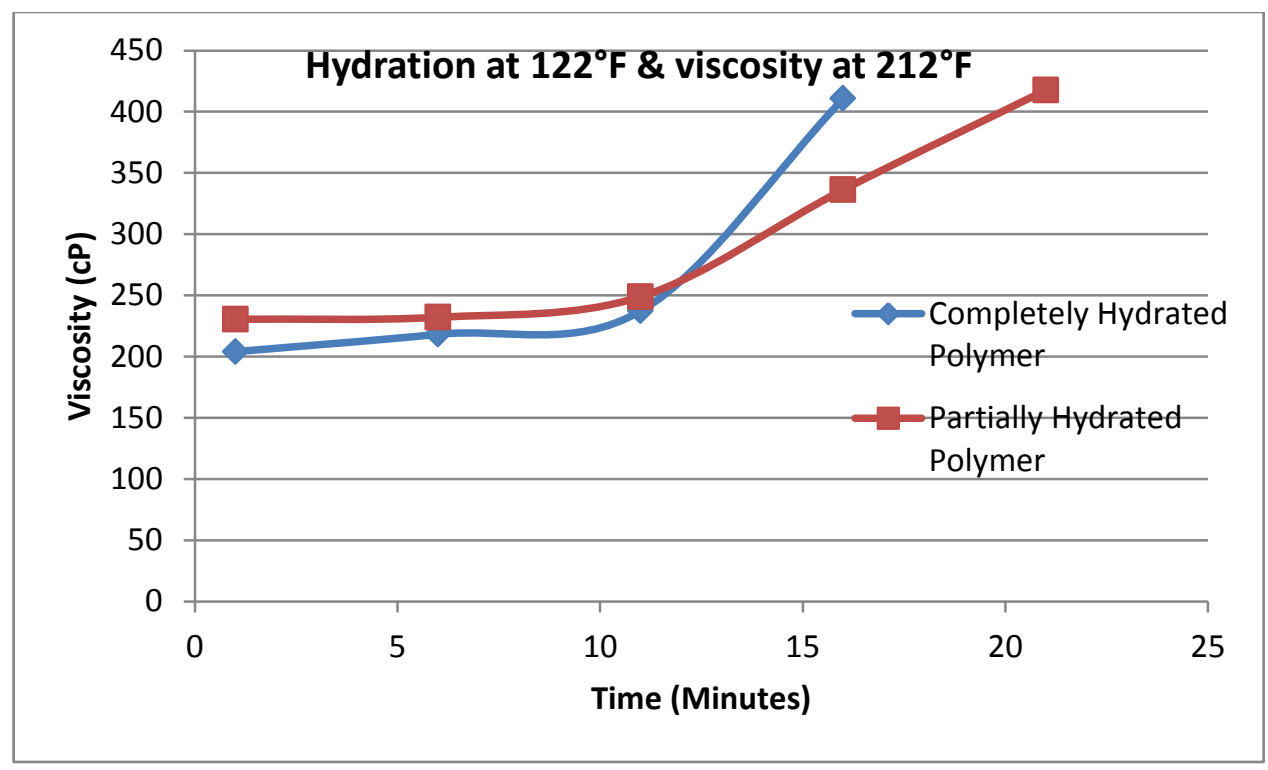

Fig. 18 - HPAM/PEI gel (9000ppm/6000ppm): Different hydration techniques

\subsection{HPAM/PEI gel (7000ppm/7000ppm) with $4 \mathrm{wt} \% \mathrm{NaCl}$}

The viscosity behavior and gel strength code for the most robust gel prepared in fresh water was 7000ppm/7000ppm HPAM/PEI. This most robust gel was also studied when hydrated at $122^{\circ} \mathrm{F}$ with $4 \mathrm{wt} \% \mathrm{NaCl}$ as shown below.

After determining that a high polymer/crosslinker concentration gave the strongest gel, the gel strength prepared with $4 \mathrm{wt} \% \mathrm{NaCl}$ for the similar concentration was compared. In most cases the polymer gels in field treatments are prepared in brines containing different concentration of salts. Sodium chloride is used to study the effect of salinity approximating that of seawater on the gelation characteristics of the organically 
crosslinked gel. As seen in Fig. 19 due to the addition of $4 w t \%$ sodium chloride the viscosity of the gelant solution has decreased with respect to gelant solution prepared in fresh water with similar polymer/crosslinker concentrations. The final $\mathrm{pH}$ of the fully hydrated polymer and the partially hydrated polymer was 9.82 and 10.88 respectively. The viscosity behavior can be seen in Fig.19 and the final gel strength for these two samples was weak but identical (gel code value of $\mathrm{C}$ ). We do not understand this phenomenon, but we simply conclude at this point that in $4 \mathrm{wt} \% \mathrm{NaCl}$ only a poor quality gel was obtained with this system.

This comparison did not seem reasonable as the final $\mathrm{pH}$ values here are lower compared to that of fresh water. So, another experiment was conducted with similar $\mathrm{pH}$ to fresh water for both fully hydrated and partially hydrated cases at 11.15 and 11.19 respectively which showed identical gel strengths after two weeks as seen in Table 5 which were identical (D). 


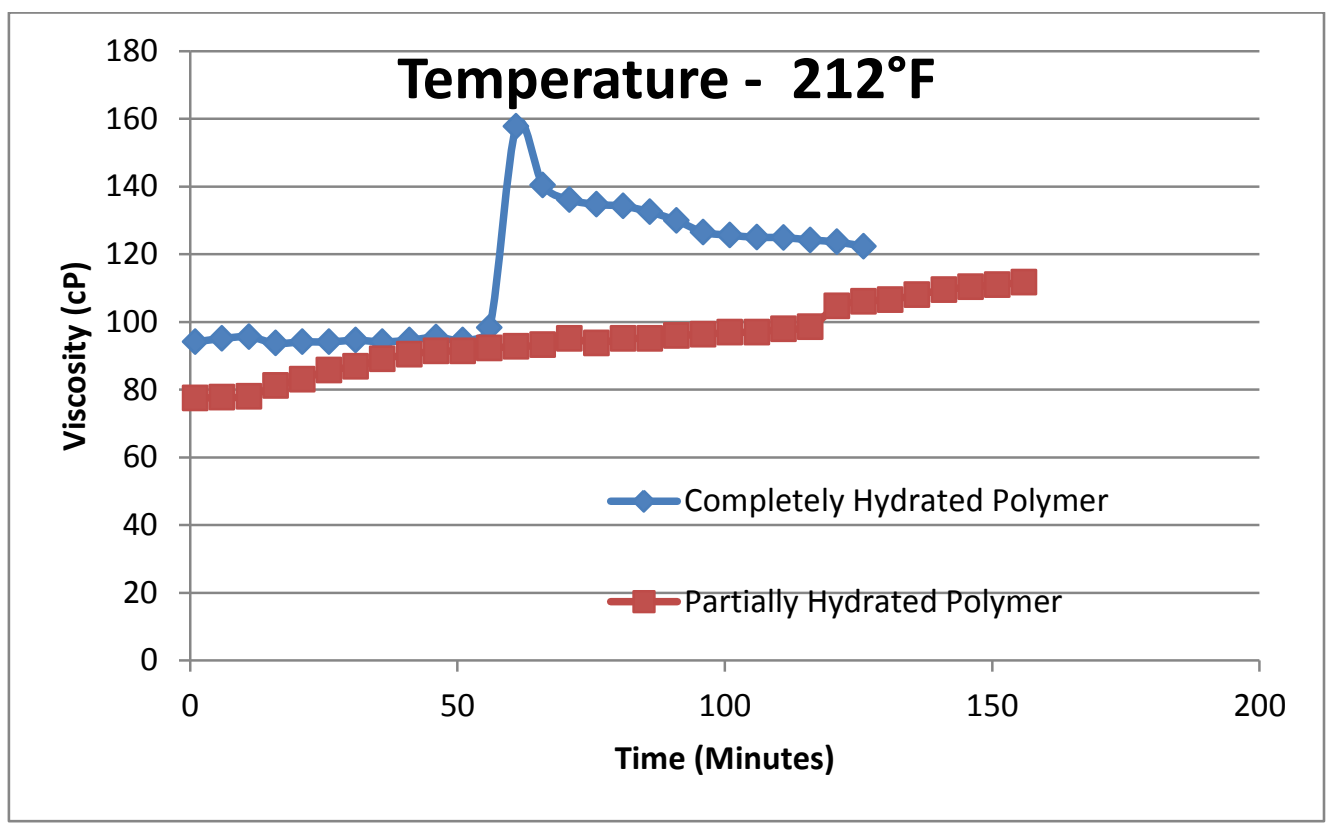

Fig. 19-HPAM/PEI gel (7000ppm/7000ppm): Different hydration techniques with $4 \mathrm{wt} \% \mathrm{NaCl}$

By choosing a robust gel concentration which in this case was 7000ppm/7000ppm of HPAM/PEI we can see in Fig. 20 that the gelation point is achieved when fresh water is used but there is no visible gelation when $4 \mathrm{wt} \% \mathrm{NaCl}$ makeup water is used. This behavior is seen due to the sodium plus chloride ions screening the positive PEI from the negative HPAM. 


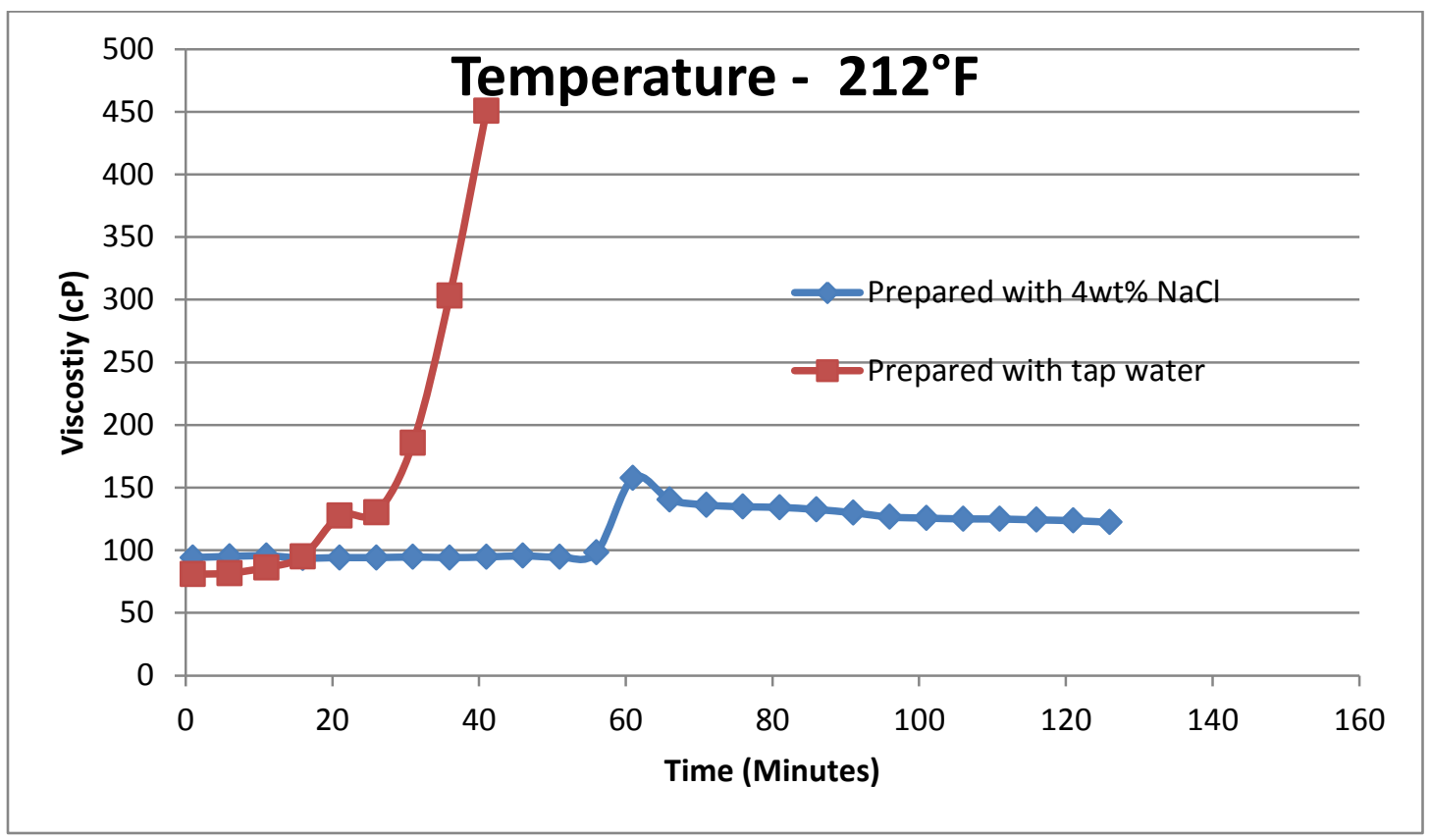

Fig. 20-HPAM/PEI gel (7000ppm/7000ppm): Similar hydration techniques with different make up water.

\subsection{Effects of variation of $\mathrm{pH}$}

The $\mathrm{pH}$ for the experiments was generally kept high due to the impurity present in the PEI. Samples prepared at a $\mathrm{pH}$ of 7 gave really weak gels and the viscosity of the polymer gel was much lower than those prepared at a $\mathrm{pH}$ of 9 and higher. A comparison between two 7000ppm/7000ppm gels with different pH has been shown in Fig. 21. This behavior shows how the degree of hydrolysis of HPAM increases under alkaline conditions providing for sites for the PEI to crosslink. 


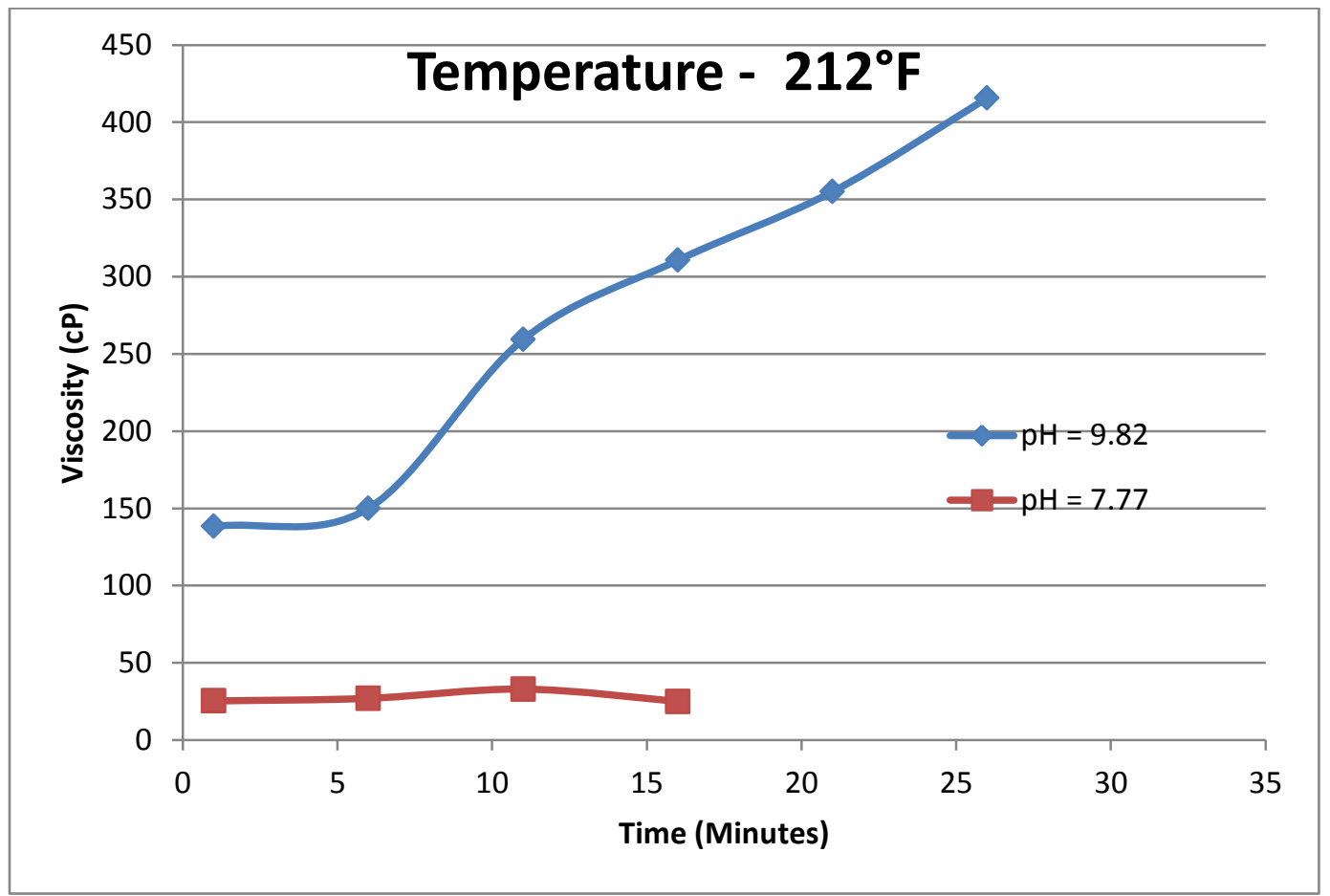

Fig. 21-HPAM/PEI gel (7000ppm/7000ppm): Similar hydration techniques with different pH.

The difference in the purity of the two samples can also be seen in the following Fig. 22. The higher $\mathrm{pH}$ polymer gel sample is much clearer due to the addition of few drops of $\mathrm{NaOH}$ than the other. 


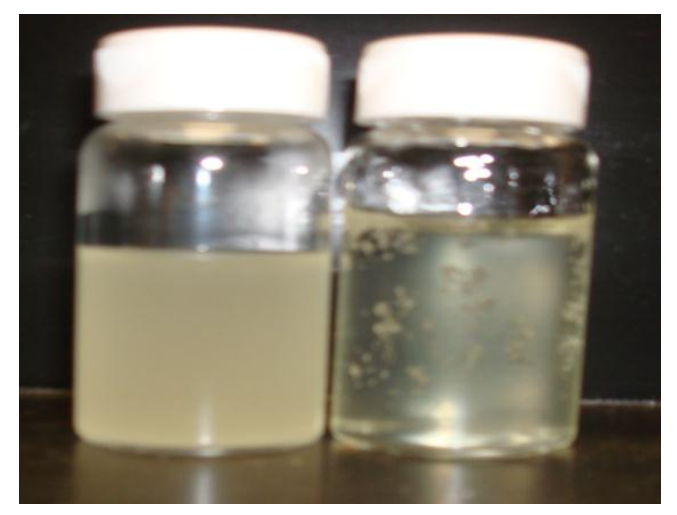

Fig. 22-(7000ppm/70000ppm) (HPAM/PEI) Samples showing difference in pH.

\subsection{Effect of hydration temperature}

The Fig. 23 below shows that if a similar concentration polymer gel is prepared at a different hydration temperatures then the gelation time decreases with increasing hydration temperature. This is a consistent behavior seen in our experiments which has also been shown previously in similar studies. 


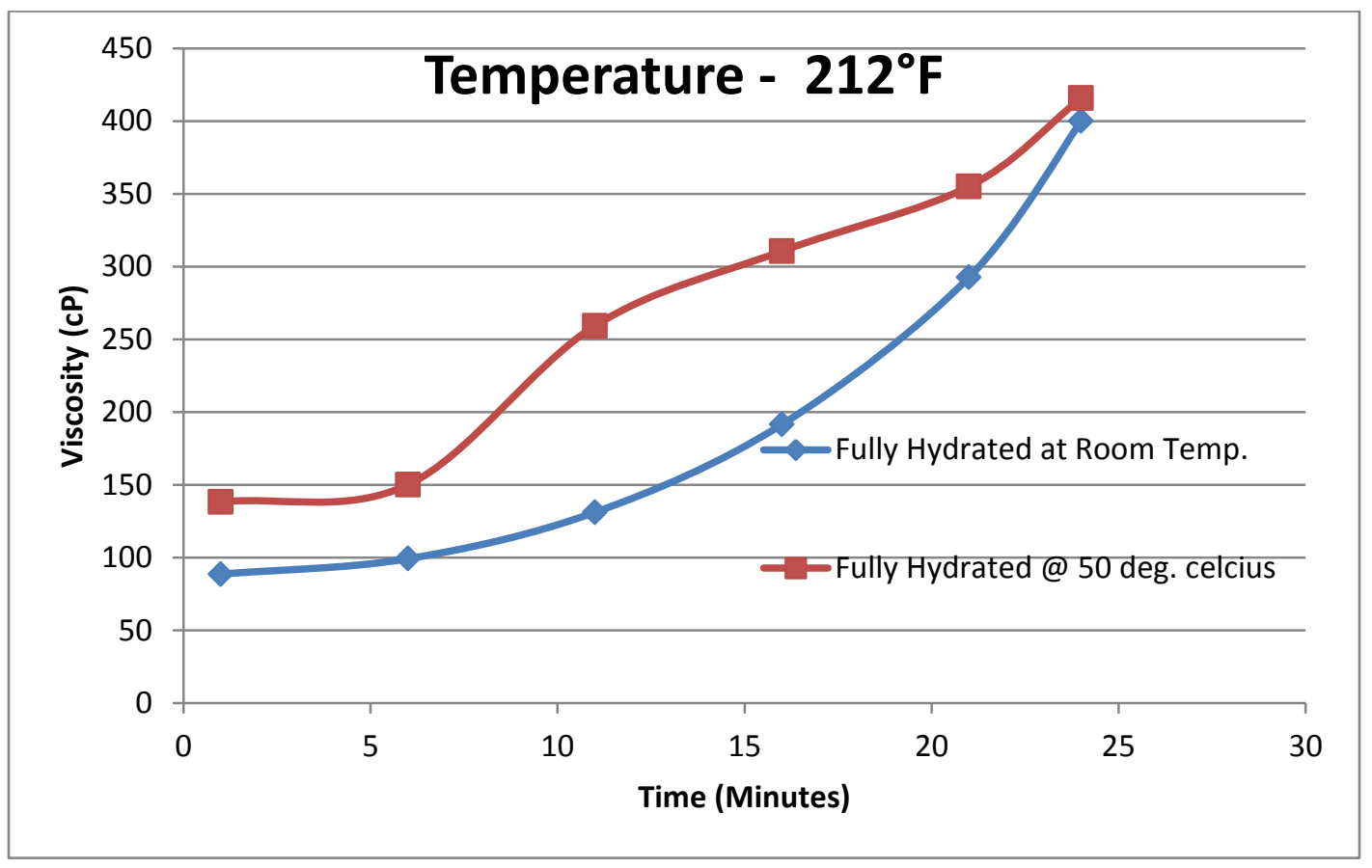

Fig. 23-HPAM/PEI gel (7000ppm/7000ppm): Similar hydration techniques with different hydration temperature.

\subsection{Effect of higher hydration temperature with $4 \mathrm{wt} \% \mathrm{NaCl}$}

In Fig. 24 we see that even after fully hydrating both polymer solution at $122^{\circ} \mathrm{F}$ for 35 mins but by using different make up water there is a huge variation in viscosity and gel strength. We can see that the hydration temperature in the case of using $4 \mathrm{wt} \%$ $\mathrm{NaCl}$ does not help in achieving a faster gelation. 


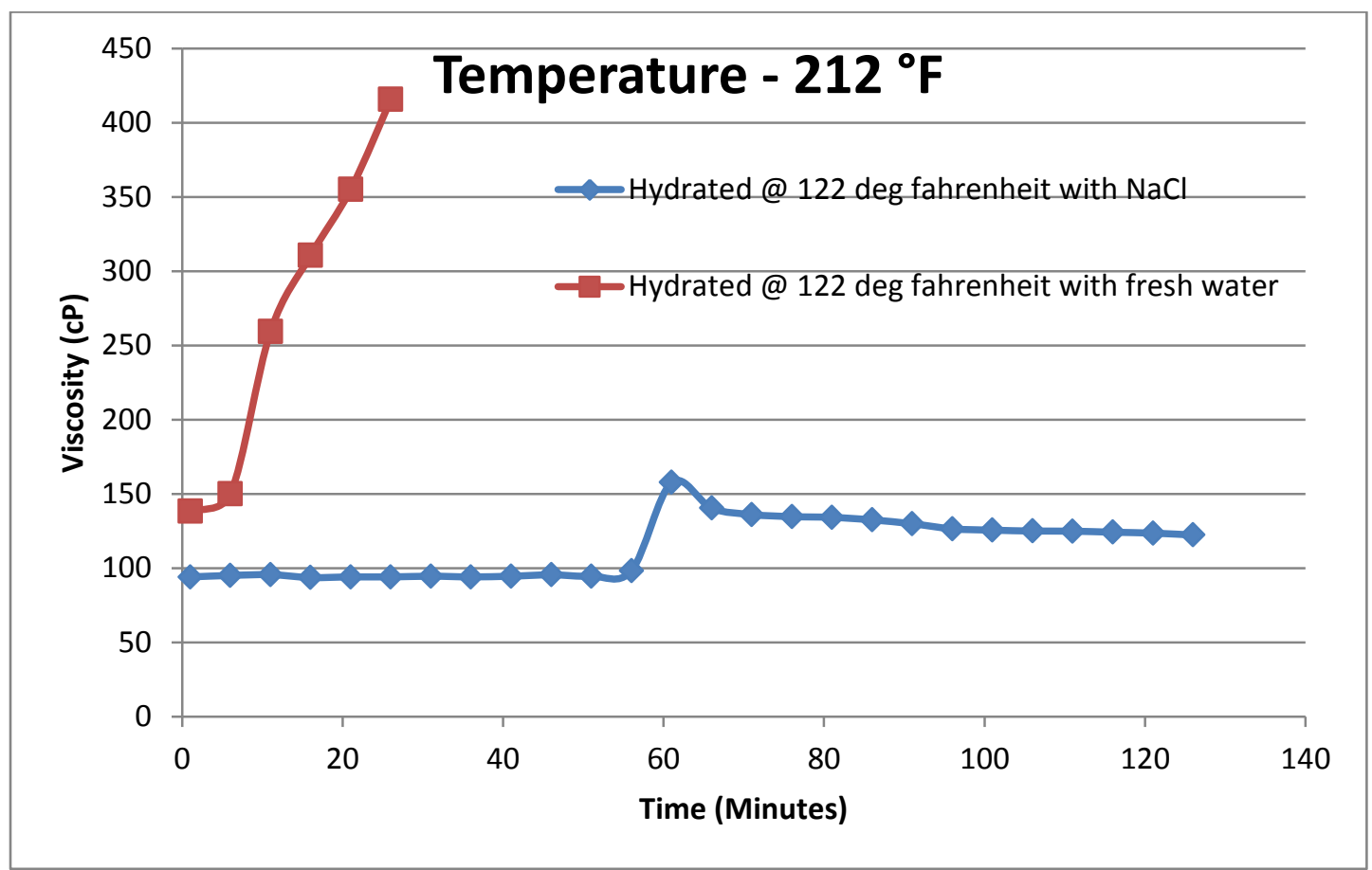

Fig. 24-HPAM/PEI gel (7000ppm/7000ppm): Similar hydration techniques with different make up water.

Table 5 below summarizes the gel strength codes of all the HPAM/PEI polymer gels prepared. 
Table 5 - Gel codes for organically crosslinked gels

\begin{tabular}{|c|c|c|c|c|c|c|}
\hline \multicolumn{7}{|c|}{ Organically crosslinked gels - Hydrated at room temperature and Stored at $200^{\circ} \mathrm{F}$} \\
\hline & \multicolumn{3}{|c|}{ Polymer/Crosslinker - } & $\mathrm{AM} / \mathrm{P}$ & & \\
\hline & \multicolumn{3}{|c|}{ Fully Hydrated Polymer } & \multicolumn{3}{|c|}{ Partially Hydrated Polymer } \\
\hline Polymer/Crosslinker Conc. & Days & Gel Strenght Code & $\mathrm{pH}$ & Days & Gel Strenght Code & $\mathrm{pH}$ \\
\hline \multirow{5}{*}{ 4000ppm / 4000ppm } & 1 & $\mathrm{D}$ & \multirow{5}{*}{9.86} & 1 & $\mathrm{D}$ & \multirow{5}{*}{9.8} \\
\hline & 2 & $\mathrm{D}$ & & 2 & $\mathrm{D}$ & \\
\hline & 4 & $\mathrm{D}$ & & 4 & $\mathrm{D}$ & \\
\hline & 7 & $\mathrm{D}$ & & 7 & $\mathrm{D}$ & \\
\hline & 14 & $\mathrm{D}$ & & 14 & $\mathrm{D}$ & \\
\hline \multirow{5}{*}{ 7000ppm/ 3000ppm } & 1 & $\mathrm{~F}$ & \multirow{5}{*}{11.49} & 1 & $\mathrm{D}$ & \multirow{5}{*}{11.69} \\
\hline & 2 & $\mathrm{~F}$ & & 2 & $\mathrm{D}$ & \\
\hline & 4 & $\mathrm{~F}$ & & 4 & $\mathrm{D}$ & \\
\hline & 7 & $\mathrm{~F}$ & & 7 & $\mathrm{E}$ & \\
\hline & 14 & $\mathrm{G}$ & & 14 & $\mathrm{E}$ & \\
\hline \multirow{5}{*}{ 7000ppm/5000ppm } & 1 & $\mathrm{G}$ & \multirow{5}{*}{9.72} & 1 & $\mathrm{G}$ & \multirow{5}{*}{9.75} \\
\hline & 2 & $\mathrm{G}$ & & 2 & $\mathrm{G}$ & \\
\hline & 4 & $\mathrm{G}$ & & 4 & $\mathrm{G}$ & \\
\hline & 7 & $\mathrm{G}$ & & 7 & $\mathrm{G}$ & \\
\hline & 14 & $\mathrm{G}$ & & 14 & $\mathrm{G}$ & \\
\hline \multirow{5}{*}{ 7000ppm/5000ppm } & 1 & $\mathrm{G}$ & \multirow{5}{*}{11.33} & 1 & $\mathrm{E}$ & \multirow{5}{*}{11.63} \\
\hline & 2 & $\mathrm{G}$ & & 2 & $\mathrm{E}$ & \\
\hline & 4 & G & & 4 & $\mathrm{E}$ & \\
\hline & 7 & $\mathrm{G}$ & & 7 & $\mathrm{E}$ & \\
\hline & 14 & G & & 14 & $\mathrm{~F}$ & \\
\hline \multirow{5}{*}{ 7000ppm/7000ppm } & 1 & $\mathrm{H}$ & \multirow{5}{*}{11.26} & 1 & $\mathrm{G}$ & \multirow{5}{*}{11.45} \\
\hline & 2 & $\mathrm{H}$ & & 2 & G & \\
\hline & 4 & $\mathrm{H}$ & & 4 & G & \\
\hline & 7 & $\mathrm{H}$ & & 7 & $\mathrm{G}$ & \\
\hline & 14 & $\mathrm{H}$ & & 14 & $\mathrm{G}$ & \\
\hline \multicolumn{7}{|c|}{ Organically crosslinked gel - Hydrated at $122^{\circ} \mathrm{F}$ with $4 \mathrm{wt} \% \mathrm{NaCl}$ and Stored at $200^{\circ} \mathrm{F}$} \\
\hline \multirow{5}{*}{ 7000ppm/7000ppm } & 1 & $\mathrm{C}$ & \multirow{5}{*}{9.82} & 1 & $\mathrm{C}$ & \multirow{5}{*}{10.88} \\
\hline & 2 & $\mathrm{C}$ & & 2 & $\mathrm{C}$ & \\
\hline & 4 & $\mathrm{C}$ & & 4 & $\mathrm{C}$ & \\
\hline & 7 & $\mathrm{C}$ & & 7 & $\mathrm{C}$ & \\
\hline & 14 & $\mathrm{C}$ & & 14 & $\mathrm{C}$ & \\
\hline & 1 & $\mathrm{D}$ & & 1 & $\mathrm{D}$ & \\
\hline & 2 & $\mathrm{D}$ & & 2 & $\mathrm{D}$ & \\
\hline 7000ppm/7000ppm & 4 & $\mathrm{D}$ & 11.15 & 4 & $\mathrm{D}$ & 11.19 \\
\hline & 7 & $\mathrm{D}$ & & 7 & $\mathrm{D}$ & \\
\hline & 14 & $\mathrm{D}$ & & 14 & $\mathrm{D}$ & \\
\hline Organically crosslinked & gel - Hyd & ated at $122^{\circ} \mathrm{F}$ with 4 & $\mathrm{vt} \% \mathrm{Na}$ & 1 and $S$ & red at $200^{\circ} \mathrm{F}($ Low 1 & H) \\
\hline & 1 & $\mathrm{C}$ & & 1 & $\mathrm{~B}$ & \\
\hline & 2 & $\mathrm{C}$ & & 2 & $\mathrm{~B}$ & \\
\hline 7000ppm/7000ppm & 4 & $\mathrm{C}$ & 9.83 & 4 & $\mathrm{~B}$ & 7.77 \\
\hline & 7 & $\mathrm{C}$ & & 7 & $\mathrm{~B}$ & \\
\hline & 14 & $\mathrm{C}$ & & 14 & $\mathrm{~B}$ & \\
\hline
\end{tabular}




\subsection{Origanically crosslinked polymer gels prepared with research grade PEI}

After studying the gel strength codes for the commercial grade PEI, a few samples with low and high polymer loading were prepared with the research grade PEI to compare the gel strengths of the two different kinds of polymer gels.

A better HPAM/PEI crosslinking was seen with the research grade PEI because of no impurities present in the crosslinker. But with the few samples prepared we can say that the final gel strength code difference between the commercial grade and research grade crosslinked polymer gels was of one code level with the research grade being the higher code level. Please, note that there was no difference in gel strength code because of different hydration techniques.

\subsection{Viscosity of pre-gel polymer solution}

The effect on viscosity of pre-gel polymer solution was studied after crosslinker addition. In Fig. 25 for a HPAM/PEI polymer system we see that the overall polymer solution viscosity dropped after crosslinker was added. Whereas in Fig. 26 for the HPAM/CrAc system the viscosity remained similar to the polymer solution when the crosslinker was added after complete hydration but increased when crosslinker was added to partially hydrated sample.

We do not understand this behavior but future experiments will be conducted with research grade PEI to fully understand this behavior.

In Fig.27 and Fig.28 an already stated fact can be observed. It shows how temperature effects gelation time. These sample were studied at ambient temperature 
hence we see a very slow increase in gelation over time for both HPAM/PEI and $\mathrm{HPAM} / \mathrm{CrAc}$.

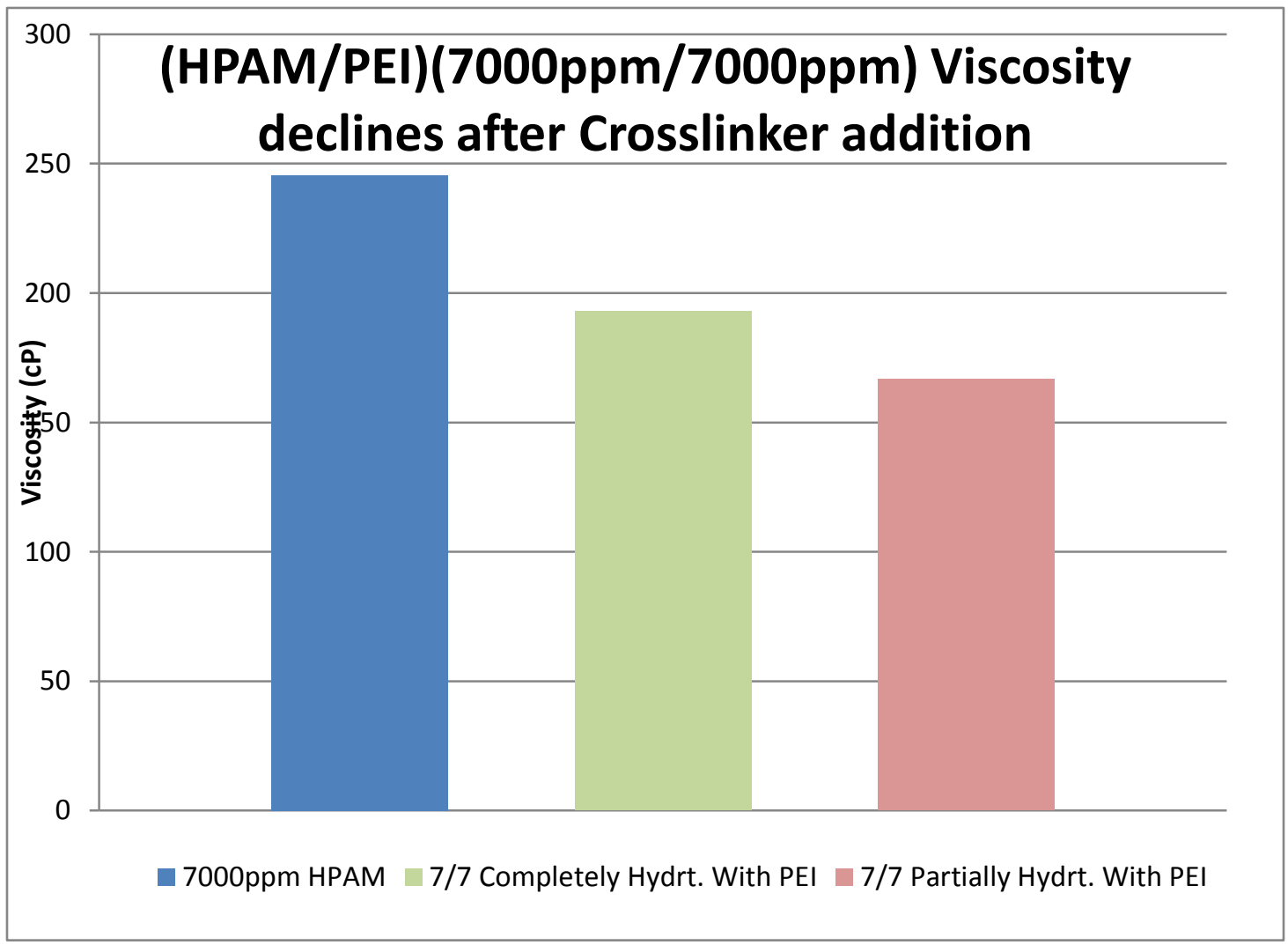

Fig. 25-HPAM/PEI gel (7000ppm/7000ppm): Pre-Gel viscosity comparison. 


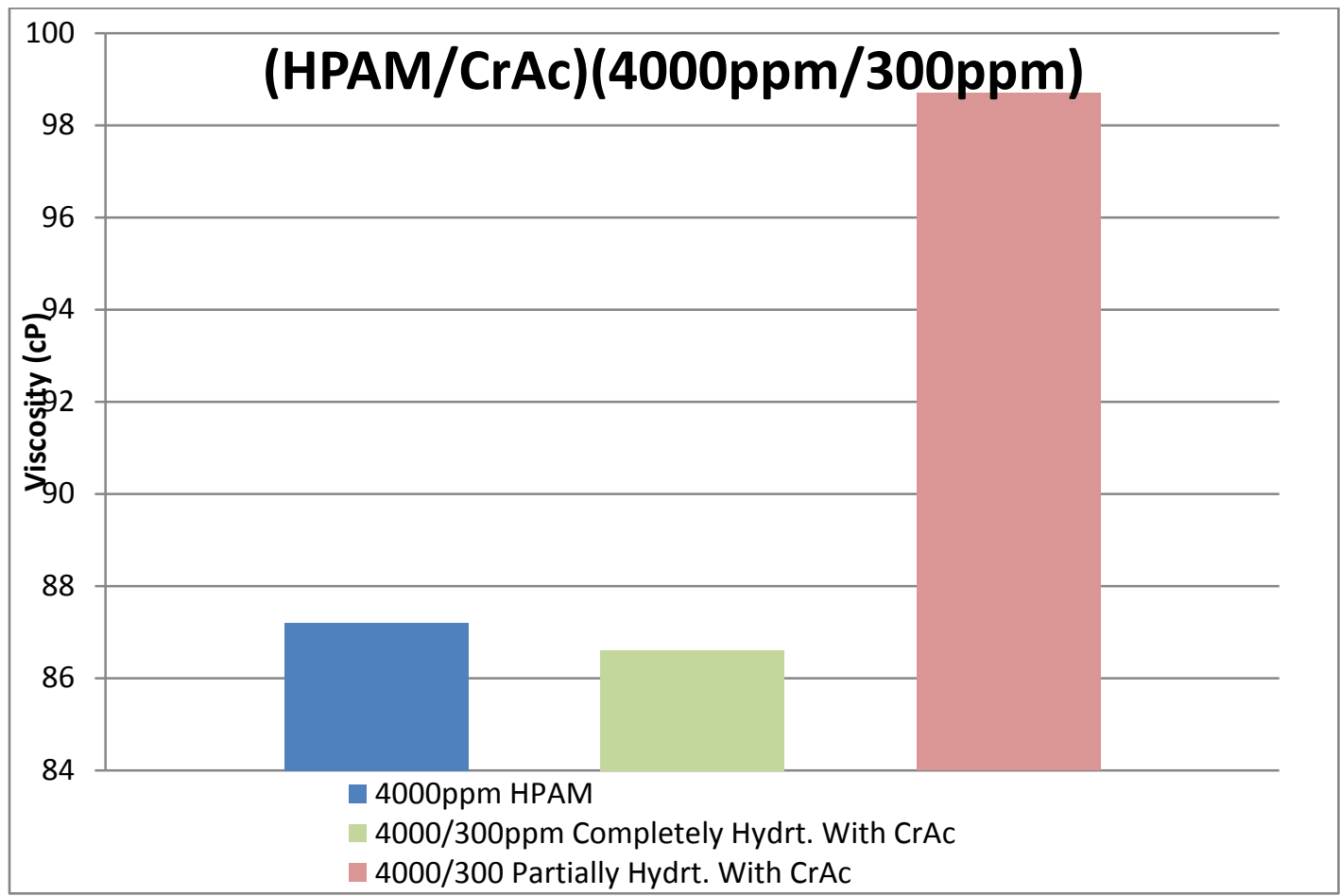

Fig. 26-HPAM/CrAc gel (4000ppm/300ppm): Pre-Gel viscosity comparison

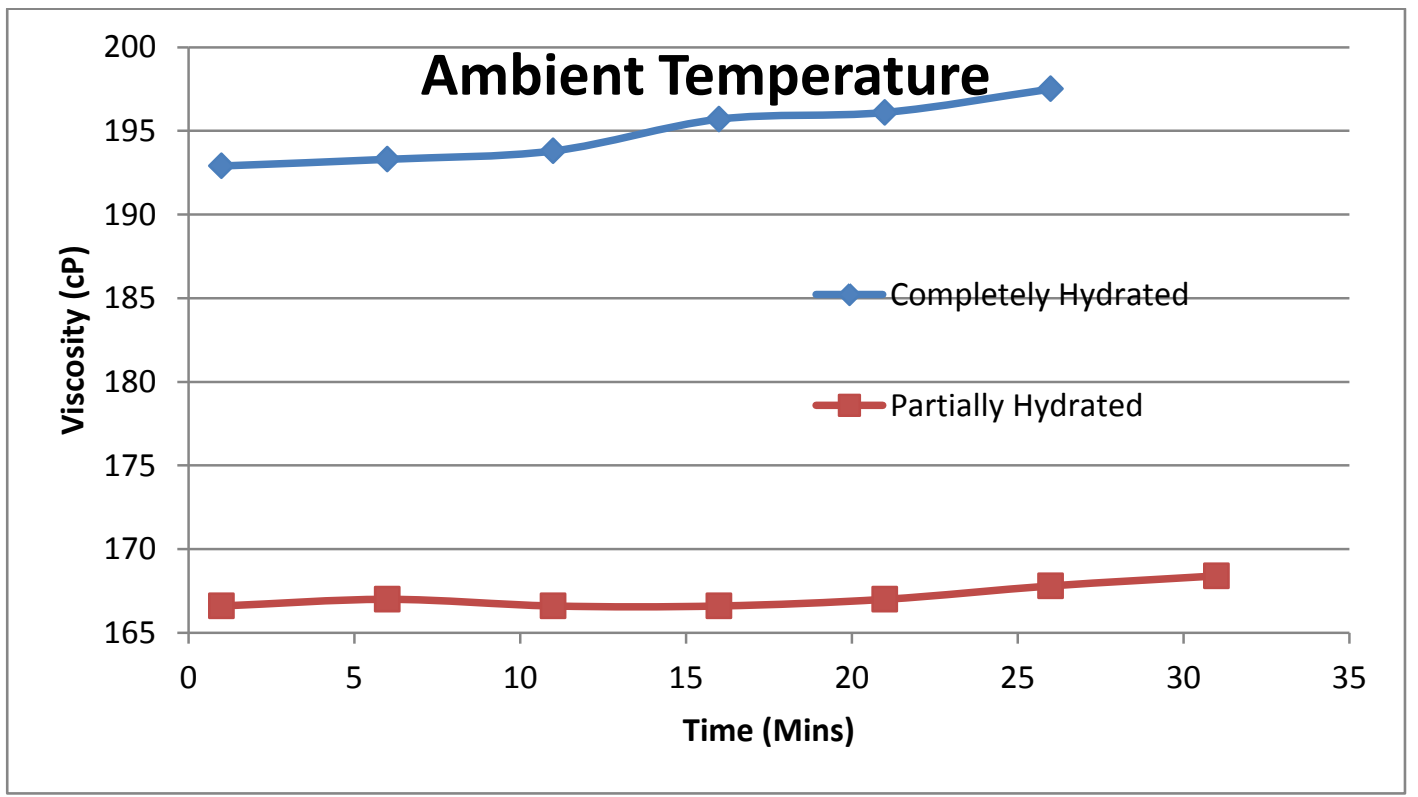

Fig. 27-HPAM/PEI gel (7000ppm/7000ppm): Viscosity behavior at ambient temperature. 


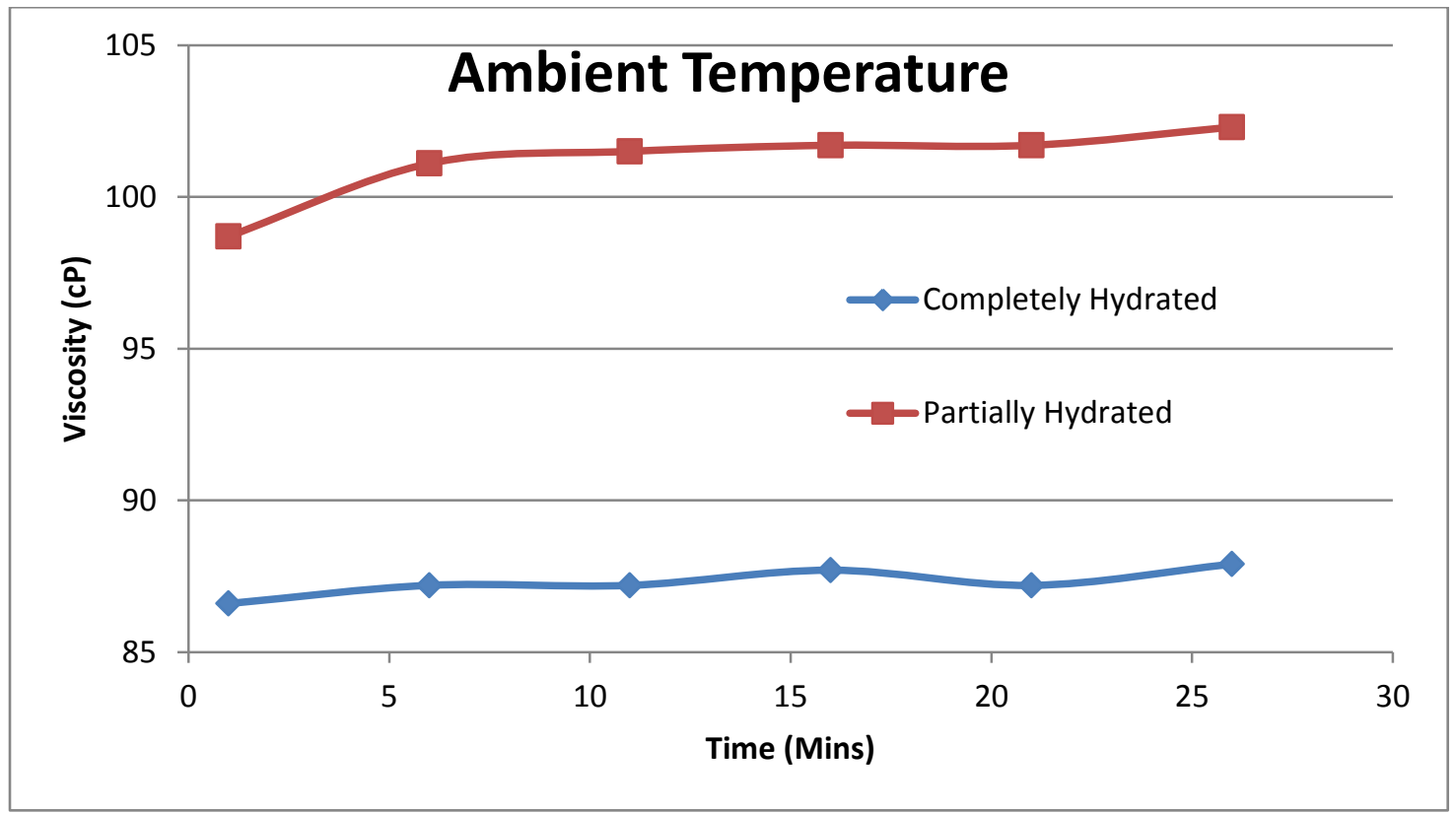

Fig. 28-HPAM/CrAc gel (4000ppm/300ppm): Viscosity behavior at ambient temperature. 
Table 6 below summarizes the results for polymer gels prepared with research grade PEI.

Table 6-Gel codes for organically crosslinked gels with research grade PEI.

\begin{tabular}{|c|c|c|c|c|c|c|}
\hline \multicolumn{7}{|c|}{ Organically crosslinked gels - Hydrated at room temperature and Stored at $200^{\circ} \mathrm{F}$} \\
\hline \multicolumn{7}{|c|}{ HPAM/PEI (Research Grade) } \\
\hline & \multicolumn{3}{|c|}{ Fully Hydrated Polymer } & \multicolumn{3}{|c|}{ Partially Hydrated Polymer } \\
\hline Polymer/Crosslinker Conc. & Days & Gel Strenght Code & $\mathrm{pH}$ & Days & Gel Strenght Code & $\mathrm{pH}$ \\
\hline \multirow{5}{*}{$5000 \mathrm{ppm} / 5000 \mathrm{ppm}$} & 1 & $\mathrm{C}$ & \multirow{5}{*}{10.24} & 1 & $\mathrm{C}$ & \multirow{5}{*}{10.25} \\
\hline & 2 & $\mathrm{C}$ & & 2 & $\mathrm{C}$ & \\
\hline & 4 & $\mathrm{C}$ & & 4 & $\mathrm{C}$ & \\
\hline & 7 & $\mathrm{C}$ & & 7 & $\mathrm{C}$ & \\
\hline & 14 & $\mathrm{C}$ & & 14 & $\mathrm{C}$ & \\
\hline \multirow{5}{*}{$9000 \mathrm{ppm} / 6000 \mathrm{ppm}$} & 1 & I & \multirow{5}{*}{10.25} & 1 & $\mathrm{I}$ & \multirow{5}{*}{10.27} \\
\hline & 2 & $\mathrm{I}$ & & 2 & $\mathrm{I}$ & \\
\hline & 4 & $\mathrm{I}$ & & 4 & $\mathrm{I}$ & \\
\hline & 7 & $\mathrm{I}$ & & 7 & $\mathrm{I}$ & \\
\hline & 14 & $\mathrm{I}$ & & 14 & $\mathrm{I}$ & \\
\hline \multicolumn{7}{|c|}{ Organically crosslinked gels - Hydrated at $122^{\circ} \mathrm{F}$ and Stored at $200^{\circ} \mathrm{F}$} \\
\hline \multicolumn{7}{|c|}{ Polymer/Crosslinker - $\quad$ HPAM/PEI (Research Grade) } \\
\hline & \multicolumn{3}{|c|}{ Fully Hydrated Polymer } & \multicolumn{3}{|c|}{ Partially Hydrated Polymer } \\
\hline Polymer/Crosslinker Conc. & Days & Gel Strenght Code & $\mathrm{pH}$ & Days & Gel Strenght Code & $\mathrm{pH}$ \\
\hline \multirow{5}{*}{$5000 \mathrm{ppm} / 5000 \mathrm{ppm}$} & 1 & $\mathrm{I}$ & \multirow{5}{*}{10} & 1 & $\mathrm{I}$ & \multirow{5}{*}{10.03} \\
\hline & 2 & I & & 2 & I & \\
\hline & 4 & I & & 4 & $\mathrm{I}$ & \\
\hline & 7 & $\mathrm{I}$ & & 7 & $\mathrm{I}$ & \\
\hline & 14 & $\mathrm{I}$ & & 14 & $\mathrm{I}$ & \\
\hline \multirow{5}{*}{$9000 \mathrm{ppm} / 6000 \mathrm{ppm}$} & 1 & $\mathrm{~J}$ & \multirow{5}{*}{10.05} & 1 & $\mathrm{~J}$ & \multirow{5}{*}{10.09} \\
\hline & 2 & $\mathrm{~J}$ & & 2 & $\mathrm{~J}$ & \\
\hline & 4 & $\mathrm{~J}$ & & 4 & $\mathrm{~J}$ & \\
\hline & 7 & $\mathrm{~J}$ & & 7 & $\mathrm{~J}$ & \\
\hline & 14 & $\mathrm{~J}$ & & 14 & $\mathrm{~J}$ & \\
\hline
\end{tabular}




\subsection{Inorganically crosslinked polymer gels}

For these types of polymer gels $100 \mathrm{wt} \%$ active powdered $\mathrm{CrAc}$ was used as a crosslinker and a high molecular weight HPAM as the polymer. After using the Sanjel software of Marathon oil the amount of chromium acetate required for the experiments was found to be as shown in Table 7.

Table 7-Polymer/Crosslinker concentration

\begin{tabular}{|c|c|c|}
\hline CrAc $(p p m)$ & HPAM $(g / 100 \mathrm{~mL})$ & $\operatorname{CrAC}(\mathrm{g} / 100 \mathrm{~mL})$ \\
\hline 500 & 0.7 & 0.05 \\
\hline 430 & 0.6 & 0.043 \\
\hline 300 & 0.5 & 0.03 \\
\hline 300 & 0.4 & 0.03 \\
\hline 200 & 0.3 & 0.02 \\
\hline
\end{tabular}

In most medium to high polymer/crosslinker concentration the HPAM/CrAc gels reached gelation time within a few seconds after being exposed to a temperature of 212 ${ }^{\circ} \mathrm{F}$ as can be seen in the flowing Fig. 29. Because of which only gel strength codes have been documented for all the polymer gel samples. 


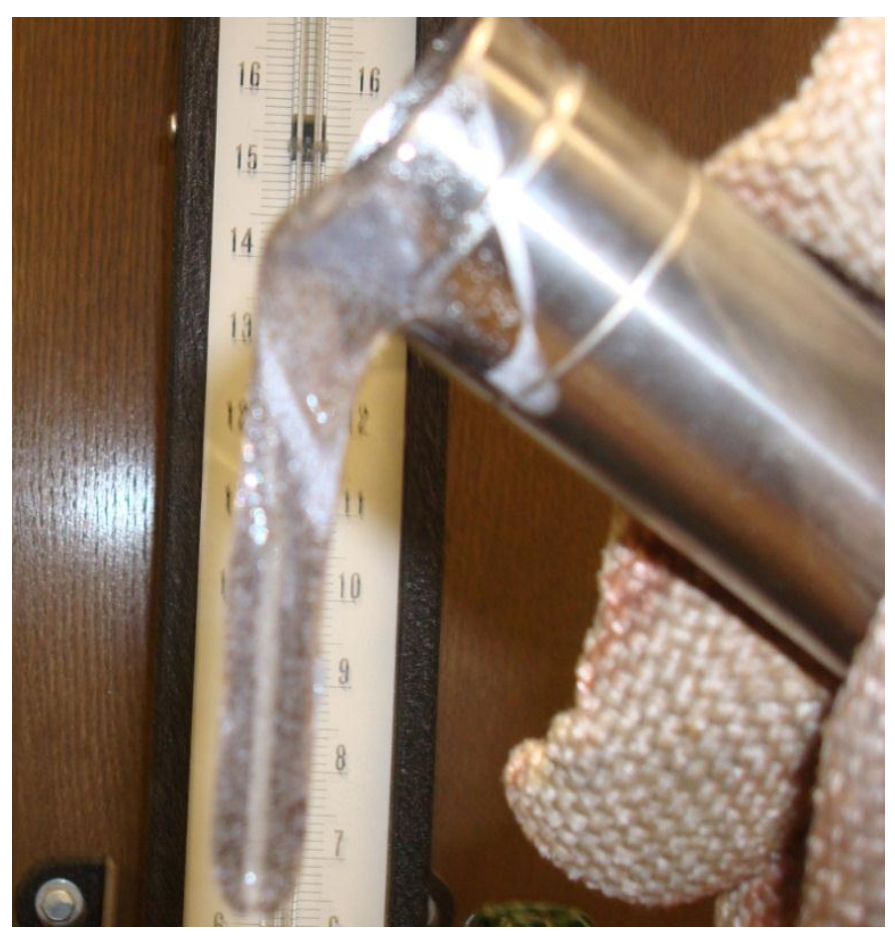

Fig. 29 - HPAM/CrAc gel (7000ppm/500ppm) sudden gelation @212 F

Table 8 below shows the gel strength codes for HPAM/CrAc polymer gels hydrated at ambient temperature and prepared with fresh water. Comparison of gel strength codes is shown for both types of hydration techniques.

The results show that the different types of hydration techniques do not change the gel strengths of the final polymer gel. But since, these samples were prepared at ambient temperature and with fresh water further experiments were conducted to study the effect of $\mathrm{NaCl}$ and hydration temperature. 
Table 8-Gel codes for inorganically crosslinked gels with fresh water

\begin{tabular}{|c|c|c|c|c|}
\hline \multicolumn{5}{|c|}{ Inorganically crosslinked gels - Hydrated at room temperature and Stored at $200^{\circ} \mathrm{F}$} \\
\hline \multicolumn{5}{|c|}{ Polymer/Crosslinker } \\
\hline & \multicolumn{2}{|c|}{ Completely Hydrated Polymer } & \multicolumn{2}{|c|}{ Partially Hydrated Polymer } \\
\hline Polymer/Crosslinker Concetration & Days & Gel Strenght Code & Days & Gel Strenght Code \\
\hline \multirow{5}{*}{ 4000ppm/300ppm } & 1 & $\mathrm{C}$ & 1 & $\mathrm{C}$ \\
\hline & 2 & $\mathrm{C}$ & 2 & $\mathrm{C}$ \\
\hline & 4 & $\mathrm{C}$ & 4 & $\mathrm{C}$ \\
\hline & 7 & $\mathrm{C}$ & 7 & $\mathrm{C}$ \\
\hline & 14 & $\mathrm{C}$ & 14 & $\mathrm{C}$ \\
\hline \multirow{5}{*}{ 5000ppm/ 300ppm } & 1 & $\mathrm{D}$ & 1 & $\mathrm{D}$ \\
\hline & 2 & $\mathrm{D}$ & 2 & $\mathrm{D}$ \\
\hline & 4 & $\mathrm{D}$ & 4 & $\mathrm{D}$ \\
\hline & 7 & $\mathrm{D}$ & 7 & $\mathrm{D}$ \\
\hline & 14 & $\mathrm{D}$ & 14 & $\mathrm{D}$ \\
\hline \multirow{5}{*}{ 6000ppm/430ppm } & 1 & $\mathrm{D}$ & 1 & $\mathrm{D}$ \\
\hline & 2 & $\mathrm{D}$ & 2 & $\mathrm{D}$ \\
\hline & 4 & $\mathrm{D}$ & 4 & $\mathrm{D}$ \\
\hline & 7 & $\mathrm{D}$ & 7 & $\mathrm{D}$ \\
\hline & 14 & $\mathrm{D}$ & 14 & $\mathrm{D}$ \\
\hline \multirow{5}{*}{$7000 \mathrm{ppm} / 500 \mathrm{ppm}$} & 1 & $\mathrm{E}$ & 1 & $\mathrm{E}$ \\
\hline & 2 & $\mathrm{E}$ & 2 & $\mathrm{E}$ \\
\hline & 4 & $\mathrm{E}$ & 4 & $\mathrm{E}$ \\
\hline & 7 & $\mathrm{E}$ & 7 & $\mathrm{E}$ \\
\hline & 14 & $\mathrm{E}$ & 14 & $\mathrm{E}$ \\
\hline \multirow{5}{*}{$9000 \mathrm{ppm} / 500 \mathrm{ppm}$} & 1 & $\mathrm{C}$ & 1 & $\mathrm{C}$ \\
\hline & 2 & $\mathrm{C}$ & 2 & $\mathrm{C}$ \\
\hline & 4 & $\mathrm{C}$ & 4 & $\mathrm{C}$ \\
\hline & 7 & $\mathrm{C}$ & 7 & $\mathrm{C}$ \\
\hline & 14 & $\mathrm{C}$ & 14 & $\mathrm{C}$ \\
\hline \multicolumn{5}{|c|}{ Inorganically crosslinked gel - Hydrated at $105^{\circ} \mathrm{F}$ and Stored at $200^{\circ} \mathrm{F}$} \\
\hline \multirow{5}{*}{$7000 \mathrm{ppm} / 500 \mathrm{ppm}$} & 1 & $\mathrm{E}$ & 1 & $\mathrm{E}$ \\
\hline & 2 & $\mathrm{E}$ & 2 & $\mathrm{E}$ \\
\hline & 4 & $\mathrm{E}$ & 4 & $\mathrm{E}$ \\
\hline & 7 & $\mathrm{E}$ & 7 & $\mathrm{E}$ \\
\hline & 14 & $\mathrm{E}$ & 14 & $\mathrm{E}$ \\
\hline
\end{tabular}


Table 9 below shows the gel strength codes for HPAM/CrAc polymer gels hydrated at ambient temperature and prepared with $4 \mathrm{wt} \% \mathrm{NaCl}$. Comparison of gel strength codes is shown for both types of hydration techniques.

Table 9-Gel codes for inorganically crosslinked gels with $4 \mathrm{wt} \% \mathrm{NaCl}$

\begin{tabular}{|c|c|c|c|c|}
\hline \multicolumn{5}{|c|}{ Inorganically crosslinked gels - Hydrated at room temperature with $4 \mathrm{wt} \% \mathrm{NaCl} \&$ Stored at $200{ }^{\circ} \mathrm{F}$. } \\
\hline \multicolumn{5}{|c|}{ Polymer/Crosslinker - $\quad$ HPAM/CrAc } \\
\hline \multirow[b]{2}{*}{ Polymer/Crosslinker Concetration } & \multicolumn{2}{|c|}{ Completely Hydrated Polymer } & \multicolumn{2}{|c|}{ Partially Hydrated Polymer } \\
\hline & Days & Gel Strength Code & Days & Gel Strength Code \\
\hline \multirow{5}{*}{ 4000ppm / 300ppm } & 1 & $\mathrm{~B}$ & 1 & $\mathrm{~B}$ \\
\hline & 2 & $\mathrm{~B}$ & 2 & $\mathrm{~B}$ \\
\hline & 4 & $\mathrm{~B}$ & 4 & $\mathrm{~B}$ \\
\hline & 7 & $\mathrm{C}$ & 7 & $\mathrm{~B}$ \\
\hline & 14 & $\mathrm{C}$ & 14 & $\mathrm{C}$ \\
\hline \multirow{5}{*}{ 5000ppm/ 300ppm } & 1 & $\mathrm{C}$ & 1 & $\mathrm{C}$ \\
\hline & 2 & $\mathrm{C}$ & 2 & $\mathrm{C}$ \\
\hline & 4 & $\mathrm{C}$ & 4 & $\mathrm{C}$ \\
\hline & 7 & $\mathrm{C}$ & 7 & $\mathrm{C}$ \\
\hline & 14 & $\mathrm{C}$ & 14 & $\mathrm{C}$ \\
\hline \multirow{5}{*}{ 6000ppm/430ppm } & 1 & $\mathrm{D}$ & 1 & $\mathrm{D}$ \\
\hline & 2 & $\mathrm{D}$ & 2 & $\mathrm{D}$ \\
\hline & 4 & $\mathrm{D}$ & 4 & $\mathrm{D}$ \\
\hline & 7 & $\mathrm{D}$ & 7 & $\mathrm{D}$ \\
\hline & 14 & $\mathrm{E}$ & 14 & $\mathrm{D}$ \\
\hline \multirow{5}{*}{ 7000ppm/500ppm } & 1 & $\mathrm{D}$ & 1 & $\mathrm{D}$ \\
\hline & 2 & $\mathrm{D}$ & 2 & $\mathrm{D}$ \\
\hline & 4 & $\mathrm{D}$ & 4 & $\mathrm{D}$ \\
\hline & 7 & $\mathrm{D}$ & 7 & $\mathrm{D}$ \\
\hline & 14 & $\mathrm{D}$ & 14 & $\mathrm{D}$ \\
\hline
\end{tabular}

So we can see that by using $4 \mathrm{wt} \% \mathrm{NaCl}$ water for polymer hydration the gel strength code was lowered by one level for 4000/300ppm and 7000/500ppm 
HPAM/CrAC gels. The presence of sodium ions does not have a huge effect on the crosslinking mechanism as for the organically crosslinked polymer gels.

Table 10 below shows the gel strength codes for HPAM/CrAc polymer gels hydrated at $122^{\circ} \mathrm{F}$ and prepared with $4 \mathrm{wt} \% \mathrm{NaCl}$. Comparison of gel strength codes is shown for both types of hydration techniques. These experiments were conducted to determine if increasing the hydration temperature for $4 \mathrm{wt} \% \mathrm{NaCl}$ make up water would give a stronger gel strength code.

Table $10-$ Gel codes for inorganically crosslinked gels with $4 \mathrm{wt} \% \mathrm{NaCl}$ hydrated at $122^{\circ} \mathrm{F}$

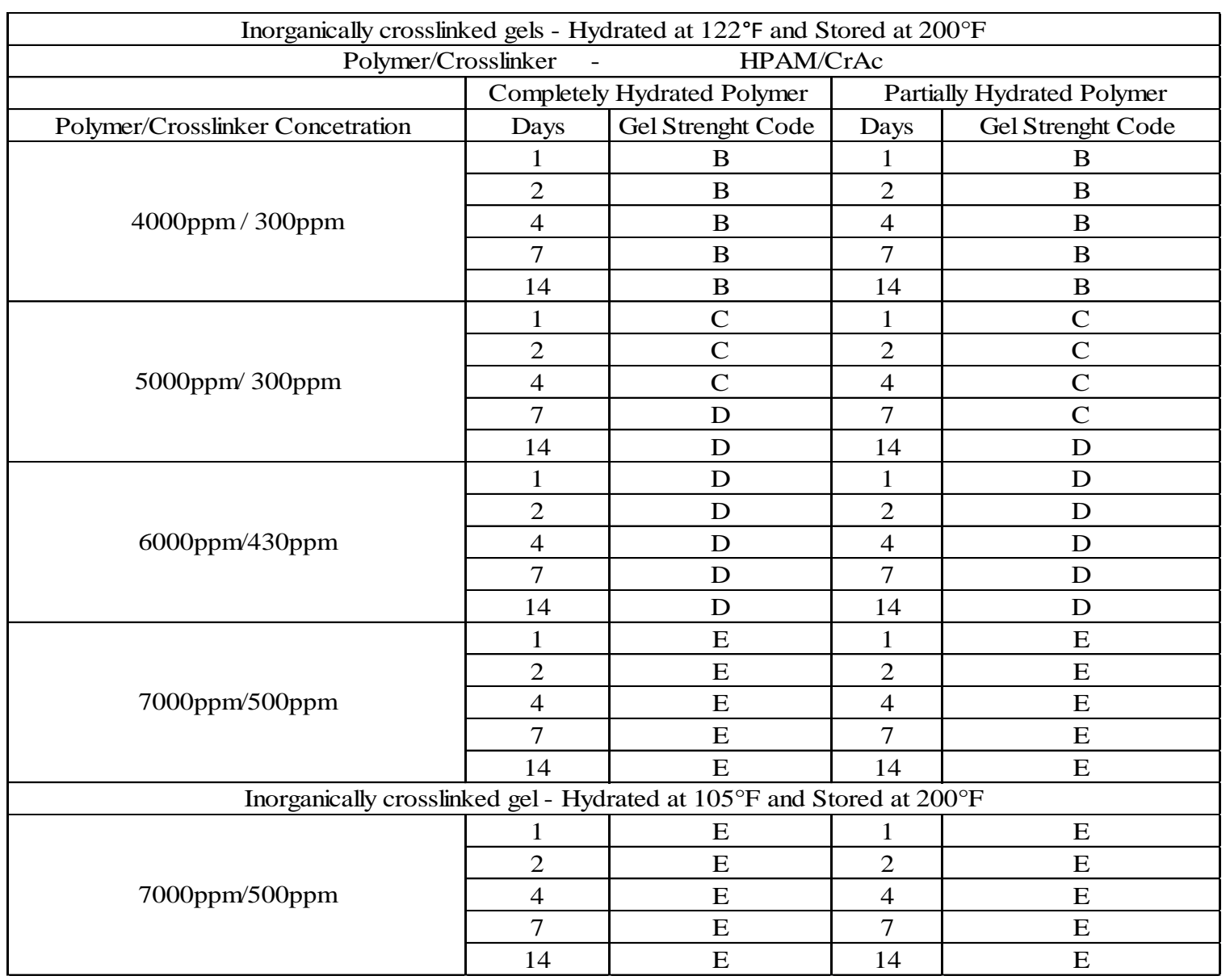


In this experiment we see that the final gel strength code increased for one concentration of 7000/500ppm HPAM/CrAc polymer gel. It was also noted during this experiment that the partially wetted polymer formed a highly viscous gelant solution within 10 minutes because of the increased hydration temperature showing that the HPAM/CrAc system gels instantly at higher hydration temperature. 


\section{CONCLUSIONS}

The conclusions can be broadly divided for the two types of polymer gels studied i.e. HPAM/PEI and HPAM/CrAc gels, compared with two types of hydration techniques i.e. partially and completely hydrated polymer.

HPAM/CrAc gels can be hydrated on-the-fly but for the HPAM/PEI gels, on-thefly hydration in not appropriate. HPAM/CrAc polymer gels for both types of hydration techniques while keeping the chemical and physical conditions identical always showed similar gel strengths.

No gelation and weaker gel strengths by more than four code units was observed for HPAM/PEI polymer gel samples when the makeup water consisted of $4 \mathrm{wt} \% \mathrm{NaCl}$ instead of fresh water. Similar behavior was seen with HPAM/CrAc polymer gels with $4 \mathrm{wt} \% \mathrm{NaCl}$ makeup water but the difference in gel strength was only one code unit weaker.

The following specific conclusions are reached from this study:

\subsection{HPAM/PEI polymer gels}

1) Most polymer gels showed similar gel strengths, regardless of the time of crosslinker addition. However, results were not consistent; a few formed weaker gels when hydrated on the fly.

2) Gel strengths were higher for samples prepared in fresh water and gradually decreased in the presence of increasing concentration of salts. 
3) All polymer gel samples gelled at $212^{\circ} \mathrm{F}$ but with a certain delay seen in partially hydrated polymer gels.

4) Gelation time decreased with increasing hydration temperature.

5) Gelation time decreased with higher $\mathrm{pH}$ value; at $\mathrm{pH}-7$ gelation did not occur.

6) In the presence of $4 \mathrm{wt} \% \mathrm{NaCl}$ in the makeup water, increasing the hydration temperature did not change gelation time at a given higher gelation temperature.

7) The viscosity of the pre-gel polymer solution decreased after crosslinker addition for both types of hydration techniques.

8) If the $\mathrm{pH}$ of a polymer solution was 11 or higher, final gel strengths were usually higher by one code level than observed when $\mathrm{pH}$ was below 11 .

\subsection{HPAM/CrAc polymer gels}

1) Inorganically crosslinked gels showed consistent gel strength for all samples with both types of hydrating techniques.

2) All inorganically crosslinked polymer gels showed similar gel strengths irrespective of polymer hydration techniques for a given set of physical and chemical conditions.

3) The major observable difference between two samples of identical composition is the capture of air bubbles. In partially hydrated samples there are more air pockets due to early crosslinking.

4) Gelation time decreased with increasing hydration temperature; for most samples the gelation occurred during the hydration step at $122^{\circ} \mathrm{F}$. 
5) Gel strength code was higher for samples prepared in fresh water and decreased with the presence of $4 \mathrm{wt} \% \mathrm{NaCl}$ by one gel strength code level.

6) In the presence of $4 \mathrm{wt} \% \mathrm{NaCl}$ make up water, gelation time increased.

7) The viscosity of the pre-gel polymer solution remained similar after crosslinker was added to completely hydrated polymer solution but increased when added to partially hydrated polymer solution. 


\section{NOMENCLATURE}

$\begin{array}{ll}\text { bpm } & \text { Barrels per minute } \\ \text { C } & \text { Celsius } \\ \text { CrAc } & \text { Chromium(III) Acetate } \\ \text { F } & \text { Fahrenheit } \\ \text { HPAM } & \text { Partially Hydrolyzed Polyacrylamide } \\ \text { PAM } & \text { Polyacrylamide } \\ \text { PEI } & \text { Polyethyleneimine } \\ \text { ppm } & \text { Parts per million }\end{array}$




\section{REFERENCES}

Al-Muntasheri, G.A., Nasr-El-Din, H.A., and Zitha, P.L.J. 2007. Gelation Kinetics and Performance Evaluation of an Organically Crosslinked Gel at High Temperature and Pressure. Paper SPE 104071 presented at the SPE First International Oil Conference and Exhibition in Mexico, Cancun, 31 August - 2 September. http://dx.doi.org/ 10.2118/104071-PA.

Bailey, B., Crabtree, M., and Tyrie, J. 2000. Water Control. Oilfield Review 12 (1): 3051.

Brookfield Engineering Laboratories, More Solutions to Sticky Problems, Inc. pg 9 Middleboro, http://www.can-am.net/suppliers/brookfield/more_solutions.pdf MA (Downloaded 12 August 2011)

Lane, R.H. 1998. Field Operational and Performance Issues of Polymeric Water-Control Agents. Paper SPE 37243 presented at the International Symposium on Oilfield Chemistry, Houston, Texas, 18-21 January 1997.

http://dx.doi.org/10.2118/37243-PA

Nasr-El-Din, H.A., and Taylor, K.C. 2005. Evaluation of Sodium Silicate/Urea Gels Used for Water Shut-off Treatments. Journal of Petroleum Science and Engineering 48 (3-4): 141-160. DOI 10.1016/j.petrol. 2005.06.010.

Nasr-El-Din, H. A., B. F. Hawkins, and Green, K.A.,1991. Viscosity Behavior of Alkaline, Surfactant, Polyacrylamide Solutions Used for Enhanced Oil Recovery. Paper SPE 21028 presented at the SPE International Symposium on Oilfield Chemistry, Anaheim, California, 20-22 February.

http://dx.doi.org/10.2118/21028-MS.

Reddy, B.R., Eoff, L., et al. 2003. A Natural Polymer-Based Cross-Linker System for Conformance Gel Systems. Paper SPE 84937 presented at the 2002 SPE/DOE Improved Oil Recovery Symposium, Tulsa, Oklahoma, 13-17 April. http://dx.doi.org/10.2118/84937-PA.

Seright, R.S. and Liang, J. 1994. A Survey of Field Applications of Gel Treatments for Water Shutoff. Paper SPE 26991 presented at the SPE Latin America/Caribbean Petroleum Engineering Conference, Buenos Aires, Argentina, 27-29 April. http://dx.doi.org/10.2118/26991-MS.

Seright, R.S., Lane, R.H., and Sydansk, R.D. 2001. A Strategy for Attacking Excess Water Production. Paper SPE 70067 presented at the SPE Permian Basin Oil and 
Gas Recovery Conference, Midland, Texas, 15-17 May. http://dx.doi.org/ 10.2118/70067-MS.

Sydansk, R. D. 1990. A Newly Developed Chromium(III) Gel Technology. SPE Reservoir Engineering. SPE Reservoir Engineering 19308. http://dx.doi.org/ 10.2118/19308-PA.

Sydansk, R.D. 2007. Polymers, Gels, Foams, and Resins. In Petroleum Engineering Handbook, ed. L.W.Lake, Vol. V(B), Chap. 13, 1149-1260. Richardson, Texas: SPE.

Syndansk, R.D. and Romero-Zerón, L.B. 2011. Reservoir Conformance Improvement. SPE, Vol. V(1), 24-29.

Syndansk, R.D. and Seright, R.S. 2007. When and Where Relative Permeability Modification Water-Shutoff Treatments Can Be Successfully Applied. Paper SPE 99371 presented at the SPE/DOE Symposium on Improved Oil Recovery, Tulsa, Oklahoma, 22-26 April.

Ward, J. S., and Martin, F. D. 1980. Prediction of Viscosity for Partially Hydrolyzed Polyacrylamide Solutions in the Presence of Calcium and Magnesium Ions. Paper SPE 8978. http://dx.doi.org/ 10.2118/8978-PA

Veil, J.A., Puder, M.G., Elcock, D., et al., 2004. A White Paper Describing Produced Water from Production of Crude Oil, Natural Gas, and Coal Bed Methane, prepared by Argonne National Laboratory, Final Report, Contract W-31-109Eng-38, U.S. Department of Energy, National Energy Technology Laboratory, Argonne, Illinois (January) 


\title{
VITA
}

\author{
Name: $\quad$ Prashant Shriwal \\ C/O Dr. Robert Lane \\ Address: $\quad$ Department of Petroleum Engineering \\ Texas A\&M University \\ 3116 TAMU - 501 Richardson Building \\ College Station, TX, 77843-3116 \\ Education: $\quad$ B. Tech., Chemical Engineering \\ Kurukshetra University (India) 2008 \\ M.S., Petroleum Engineering, Texas A\&M University, 2012 \\ Email Address: prashant.shriwal@gmail.com
}

